\title{
Identification, prevalence and pathogenicity of Colletotrichum species causing anthracnose of Capsicum annuum in Asia
}

Dilani D. de Silva ${ }^{1 *}$, Johannes Z. Groenewald² , Pedro W. Crous ${ }^{2}$, Peter K. Ades ${ }^{3}$, Andi Nasruddin ${ }^{4}$, Orarat Mongkolporn ${ }^{5}$ and Paul W. J. Taylor ${ }^{1}$ (D)

\begin{abstract}
Anthracnose of chili (Capsicum spp.) causes major production losses throughout Asia where chili plants are grown. A total of 260 Colletotrichum isolates, associated with necrotic lesions of chili leaves and fruit were collected from chili producing areas of Indonesia, Malaysia, Sri Lanka, Thailand and Taiwan. Colletotrichum truncatum was the most commonly isolated species from infected chili fruit and was readily identified by its falcate spores and abundant setae in the necrotic lesions. The other isolates consisted of straight conidia (cylindrical and fusiform) which were difficult to differentiate to species based on morphological characters. Taxonomic analysis of these straight conidia isolates based on multi-gene phylogenetic analyses (ITS, gapdh, chs-1, act, tub2, his3, ApMat, gs) revealed a further seven known Colletotrichum species, C. endophyticum, C. fructicola, C. karsti, C. plurivorum, C. scovillei, C. siamense and C. tropicale. In addition, three novel species are also described as C. javanense, C. makassarense and C. tainanense, associated with anthracnose of chili fruit in West Java (Indonesia); Makassar, South Sulawesi (Indonesia); and Tainan (Taiwan), respectively. Colletotrichum siamense is reported for the first time causing anthracnose of Capsicum annuum in Indonesia and Sri Lanka. This is also the first report of C. fructicola causing anthracnose of chili in Taiwan and Thailand and C. plurivorum in Malaysia and Thailand. Of the species with straight conidia, C. scovillei (acutatum complex), was the most prevalent throughout the surveyed countries, except for Sri Lanka from where this species was not isolated. Colletotrichum siamense (gloeosporioides complex) was also common in Indonesia, Sri Lanka and Thailand. Pathogenicity tests on chili fruit showed that C. javanense and C. scovillei were highly aggressive, especially when inoculated on non-wounded fruit, compared to all other species. The existence of new, highly aggressive exotic species, such as C. javanense, poses a biosecurity risk to production in countries which do not have adequate quarantine regulations to restrict the entry of exotic pathogens.
\end{abstract}

Keywords: Phylogenetics, Plant pathology, New taxa

\section{INTRODUCTION}

Colletotrichum is one of the most important genera of plant pathogenic fungi with many of the 200 plus species known to cause disease in plant crops worldwide (Udayanga et al. 2013; Marin-Felix et al. 2017). Colletotrichum species causing anthracnose are particularly important as post-harvest pathogens of fruit and vegetable crops

\footnotetext{
* Correspondence: paulwjt@unimelb.edu.au

${ }^{1}$ Faculty of Veterinary and Agricultural Sciences, The University of Melbourne, Parkville, VIC 3010, Australia

Full list of author information is available at the end of the article
}

growing in tropical and subtropical climates (Alahakoon et al. 1994; Rojas et al. 2010; Cannon et al. 2012; Damm et al. 2012a, 2012b; Udayanga et al. 2013; Shivas et al. 2016; De Silva et al. 2017a).

Chili (Capsicum spp.) is an important vegetable crop in tropical and subtropical climates and the fresh or dried fruit is a major culinary ingredient in many cuisines. Anthracnose is a major disease of chili fruit causing significant yield loss as well as reducing the marketability of the fruit. Anthracnose of chili has been shown to be caused by 24. Colletotrichum species (Mongkolporn and 
Taylor 2018) reported from many countries including Australia (De Silva et al. 2017a), Brazil (de Oliveira et al. 2017), China (Diao et al. 2017), India (Sharma and Shenoy 2014), Indonesia (Voorrips et al. 2004), Korea (Kim et al. 1999), Malaysia (Noor and Zakaria 2018), Sri Lanka (Ranathunge et al. 2009), Thailand (Than et al. 2008) and the USA (Harp et al. 2008).

Colletotrichum species causing anthracnose of chili in Asia were previously identified as C. acutatum (straight conidia with acute ends), C. gloeosporioides (straight conidia with obtuse ends) and C. truncatum (falcate conidia) (Than et al. 2008, Mongkolporn et al. 2010,). However, with the implementation of multigene phylogenetic analyses, $C$. acutatum was demonstrated to be a species complex (acutatum complex) composed of 34 closely related species (Marin-Felix et al. 2017), with seven species identified as causing anthracnose in chili (Mongkolporn and Taylor 2018). Similarly, C. gloeosporioides was shown to be a species complex of 38 closely related species (Marin-Felix et al. 2017), with nine species identified to cause anthracnose in chili (Mongkolporn and Taylor 2018). Morphological characters cannot differentiate many of the species with straight conidia, especially those in the acutatum and gloeosporioides complexes that are pathogens of chili, and thus multigene phylogenetic analyses are required for proper identification of these species (De Silva et al. 2017a).

The distribution of the Colletotrichum species that cause anthracnose of chili is quite variable across countries that produce this crop. For example, in Australia only six out of the 24 Colletotrichum pathogens of chili have been identified (De Silva et al. 2017a), in Thailand only three have been reported (Mongkolporn and Taylor 2018), and five from Malaysia (Noor and Zakaria 2018). In most of the previous reports the identification of species was based only on morphological data. Therefore, the status of the taxonomy of Colletotrichum spp. causing anthracnose in chili producing countries in Asia remains uncertain. Proper identification of these pathogens is important for mitigating the risk of incursion of new pathogens which if happens, may have devastating consequences for the local industries. In addition, accurate identification of the species is important for resistance breeding programs and in identifying the host-range of species. Several Colletotrichum species such as C. karsti, C. siamense and C. truncatum have broad host ranges (Cannon et al. 2012; Damm et al. 2012b). The main Colletotrichum species causing anthracnose in chili are known to be in the acutatum and gloeosporioides complexes. However, recently further species from the boninense and orchidearum complexes were implicated (Diao et al. 2017; Damm et al. 2019). Therefore, it is important to understand the taxonomy, diversity and pathogenicity of Colletotrichum species that infect chili and their distribution across countries.

The aims of the study were to (1) identify the Colletotrichum species with straight conidia (cylindrical and fusiform) causing anthracnose of chili in selected regions of Indonesia, Malaysia, Taiwan, Thailand and Sri Lanka, and (2) determine the pathogenicity of those species on chili.

\section{MATERIALS AND METHODS}

\section{Isolates}

A total of 260 isolates associated with anthracnose disease symptoms on chili fruit and leaves were collected from chili producing countries in Asia: Indonesia, Malaysia, Taiwan, Thailand, and Sri Lanka (Table 1). Type specimens and ex-type cultures are deposited in the Westerdijk

Table 1 Collection sites and numbers of Colletotrichum isolates

\begin{tabular}{|c|c|}
\hline Country and region & Number of isolates \\
\hline Thailand & 96 \\
\hline Chiang Mai & 20 \\
\hline Chiang Rai & 44 \\
\hline Kanchana Buri & 4 \\
\hline Nakhon Pathom & 7 \\
\hline Suphan Buri & 12 \\
\hline Ratchaburi & 7 \\
\hline Bangkok & 2 \\
\hline Malaysia & 12 \\
\hline Pahang & 3 \\
\hline Johor & 4 \\
\hline Kelantan & 5 \\
\hline Sri Lanka & 19 \\
\hline Kandy & 5 \\
\hline Matara & 14 \\
\hline Indonesia & 113 \\
\hline Gowa & 31 \\
\hline Soppeng & 6 \\
\hline Jeneponto & 45 \\
\hline Makassar & 7 \\
\hline Maros & 4 \\
\hline West Java (East West Seed Co. Indonesia) & 20 \\
\hline Taiwan (World Vegetable Center collection) & 20 \\
\hline Tainan & 14 \\
\hline Taichung & 1 \\
\hline Nantou & 2 \\
\hline Pingtung & 1 \\
\hline Ilan & 1 \\
\hline Hsinchu & 1 \\
\hline
\end{tabular}

Figures in bold represent the total number of isolates from each country 
Fungal Biodiversity Institute, Utrecht, The Netherlands (CBS), and in the University of Melbourne culture collection (UOM), Victoria, Australia.

Fungal isolates were established from lesions on infected fruit and leaves using two methods. Surface sterilised ( $\sim 1 \%$ ai sodium hypochlorite for $5 \mathrm{~min}$ ) infected tissue $\left(0.5 \mathrm{~cm}^{2}\right)$ was cultured on water agar (WA; Crous et al. 2009) and then after 2 to $3 \mathrm{~d}$ fungal hyphae were subcultured onto potato dextrose agar (PDA, Difco) and synthetic nutrient-poor agar (SNA, Nirenberg 1976) as described by De Silva et al. (2017a). Freshly collected fruit from field grown chili plants with typical anthracnose lesions was incubated for 1 to $2 \mathrm{~d}$ in a moist chamber until conidiomata appeared and then single spore isolation was performed according to Choi et al. (1999). Selected isolates were also cultured on oatmeal agar (OA; Crous et al. 2009) and malt extract agar (MEA) at $20^{\circ} \mathrm{C}$ under near UV light with a $12 \mathrm{~h}$ photoperiod for $10 \mathrm{~d}$. Cultures were isolated and maintained either at the AQIS quarantine laboratory at the University of Melbourne or the Evolutionary Pathology Laboratory at the Westerdijk Fungal Biodiversity Institute, Netherlands (CBS).

\section{Morphology}

Cultures grown on PDA at $27^{\circ} \mathrm{C}$ were used for morphological analysis. Colony colour and texture were examined after $10 \mathrm{~d}$, and colony growth rate calculated by measuring colony diameter 7 and $10 \mathrm{~d}$ after incubation.

Conidia from the conidiomata in culture were mounted in lactic acid and the length and width measured for 30 randomly selected conidia for each isolate, with the range and mean calculated. Size and shape of appressoria were determined on WA using a slide culture technique (Johnston and Jones 1997). Production of acervular conidiomata was observed on dried, sterilised chili peduncles inoculated with mycelia and incubated on WA and SNA media. Cultures were examined periodically for the development of perithecia. Ascospores were measured and described from perithecia squashed in lactic acid. Morphological characters were examined using a Leica DM6000 LED compound microscope with differential interference contrast (DIC) optics.

\section{DNA extraction, PCR amplification and sequencing}

The 260 Colletotrichum isolates were initially identified on the basis of culture characteristics on PDA (based on distinct morphotype groups), morphology of the spores, and/or internal transcribed spacer and intervening 5.8S nrDNA gene (ITS) sequence. A total of 115 isolates were identified as C. truncatum and the remaining 145 isolates with straight conidia were subsequently selected for multigene phylogenetic analyses. Genomic DNA was extracted from fresh mycelia grown on PDA using the
DNeasy Plant Mini kit (QIAGEN, Australia), following the manufacturer's instructions. DNA quality was assessed on a $1.4 \%(\mathrm{w} / \mathrm{v})$ agarose gel, quantified by comparing with a known amount of Lambda DNA/HindIII marker (Invitrogen, Australia), diluted to $2 \mathrm{ng} / \mu \mathrm{L}$ and then stored at $-20{ }^{\circ} \mathrm{C}$ until ready for PCR.

Isolates belonging to the acutatum complex were further analysed with partial gene sequences of five genomic loci: an intron sequence of the glyceraldehyde-3-phosphate dehydrogenase ( gapdh), partial sequences of the chitin synthase 1 (chs-1), actin (act), beta-tubulin (tub2) and histone 3 (his3) genes. Isolates of the gloeosporioides complex were further analysed with chs-1, act, gapdh, tub2, Apn2-MAT1-2 intergenic spacer and partial mating type MAT1-2 gene (ApMat) and glutamine synthetase $(g s)$ genes. Isolates belonging to the boninense and orchidearum complexes were further analysed with gapdh, tub2 and act genes. The genes were amplified and sequenced using the respective primer pairs for each gene region: ACT-512F + ACT-783R (act; Carbone and Kohn 1999), AMF1 + AMR1 (ApMat; Silva et al. 2012b), CHS-79F + CHS-345R (chs-1; Carbone and Kohn 1999), GDF1 + GDR1 (gapdh; Guerber et al. 2003), GSF1 + GSR1 ( $g s$; Stephenson et al. 1997), CYLH3F + CYLH3R (his3; Crous et al. 2004a), ITS1 + ITS4 (ITS; White et al. 1990), and Btub2Fd + Btub4Rd (tub2; Woudenberg et al. 2009).

The PCR for each reaction was performed in a 2720 Thermal Cycler (Applied Biosystems) in a total volume of $25 \mu \mathrm{L}$, comprised of $1 \times$ PCR buffer, $0.2 \mathrm{mM}$ dNTP, $0.4 \mu \mathrm{M}$ of each primer, $2 \mathrm{mM} \mathrm{MgCl}_{2}, 1 \mathrm{U}$ Taq DNA polymerase (MangoTaq DNA polymerase; Bioline) and $6 \mathrm{ng}$ template DNA and components were adjusted as required. PCR amplification protocols were performed as described by Damm et al. (2012a, 2012b) and Silva et al. (2012), except for the annealing temperatures which were adjusted to $55^{\circ} \mathrm{C}$ for ITS, gapdh, tub2, $58{ }^{\circ} \mathrm{C}$ for act, $60^{\circ} \mathrm{C}$ for $g s$ and $62^{\circ} \mathrm{C}$ for ApMat.

All PCR products were purified with the QIAquick PCR Purification kit (QIAGEN, Australia), according to manufacturer's instructions. DNA sequence analysis of the PCR products was carried out at either the Australian Genome Research Facility (AGRF, Melbourne) or at the Westerdijk Fungal Biodiversity Institute, Utrecht, the Netherlands. The purified PCR products were sequenced in both forward and reverse directions, and the consensus sequences were obtained by alignment using Geneious Pro v. 11.1.4 (Kearse et al. 2012). The consensus sequences were deposited in GenBank (Table 2) and taxonomic novelties in MycoBank (Crous et al. 2004b). Sequences of each locus were assembled with MEGA v. 6 (Tamura et al. 2013). GenBank accession numbers of all the isolates used in the phylogenetic analyses are listed in Table 2. 


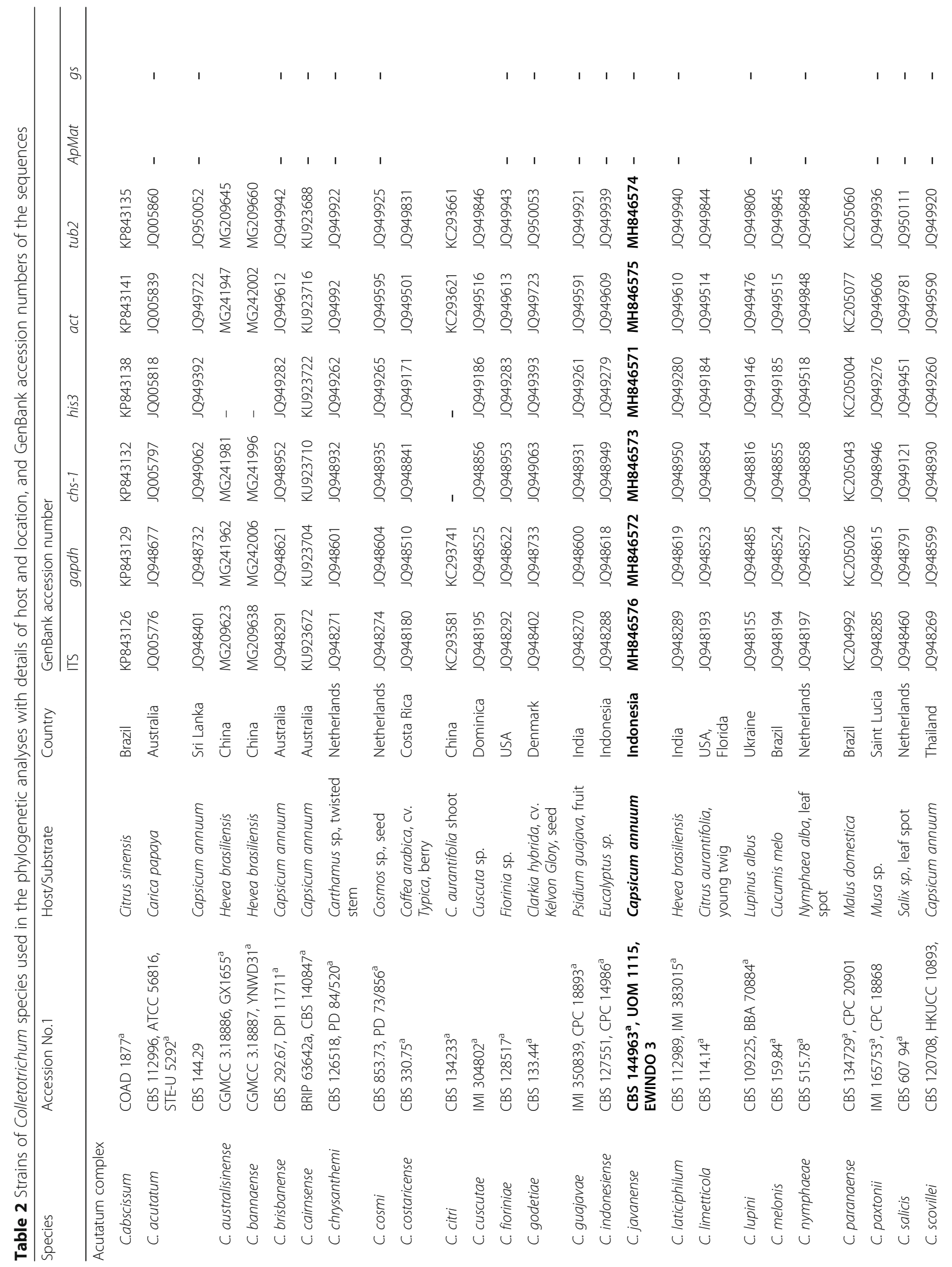




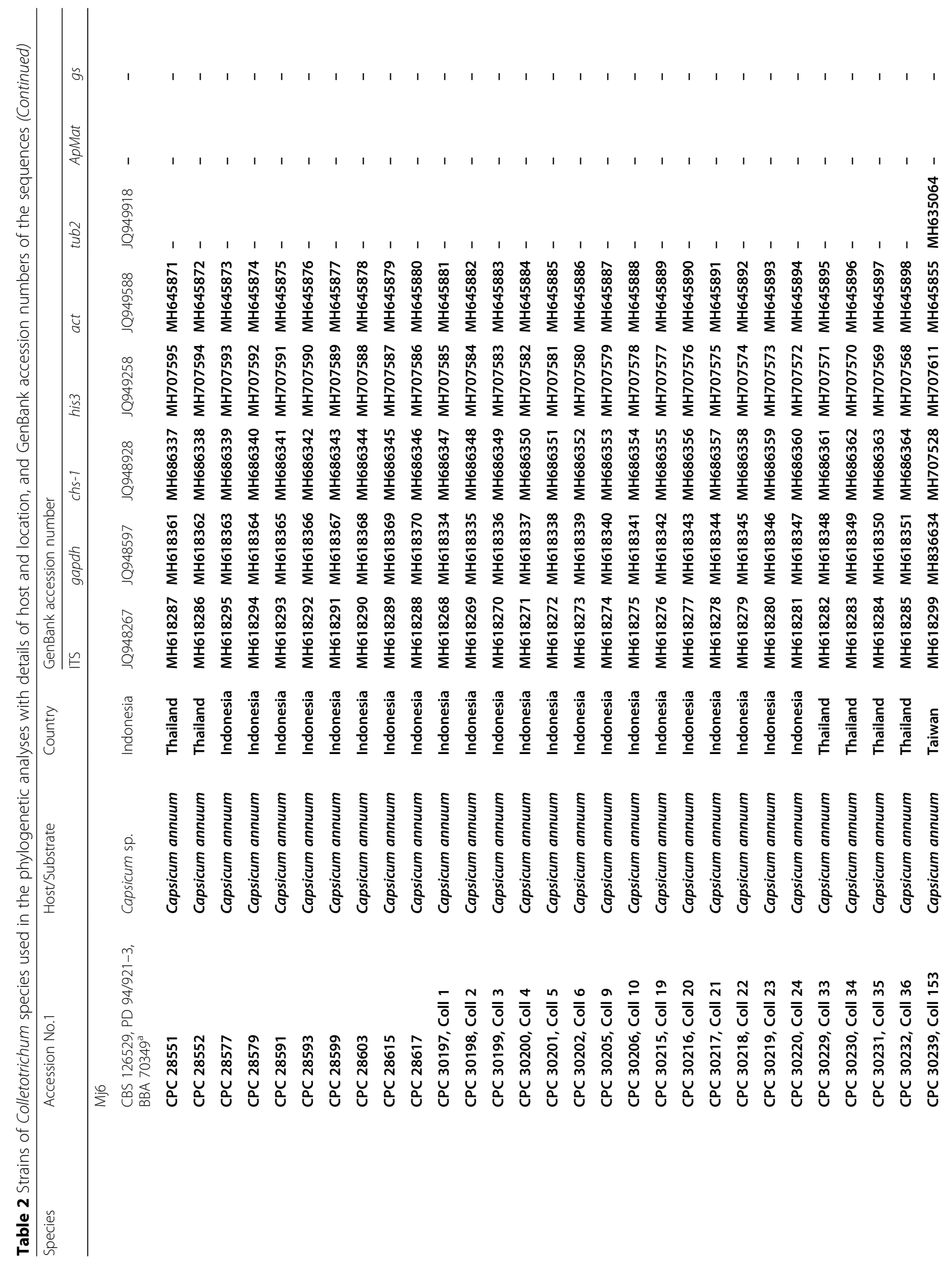




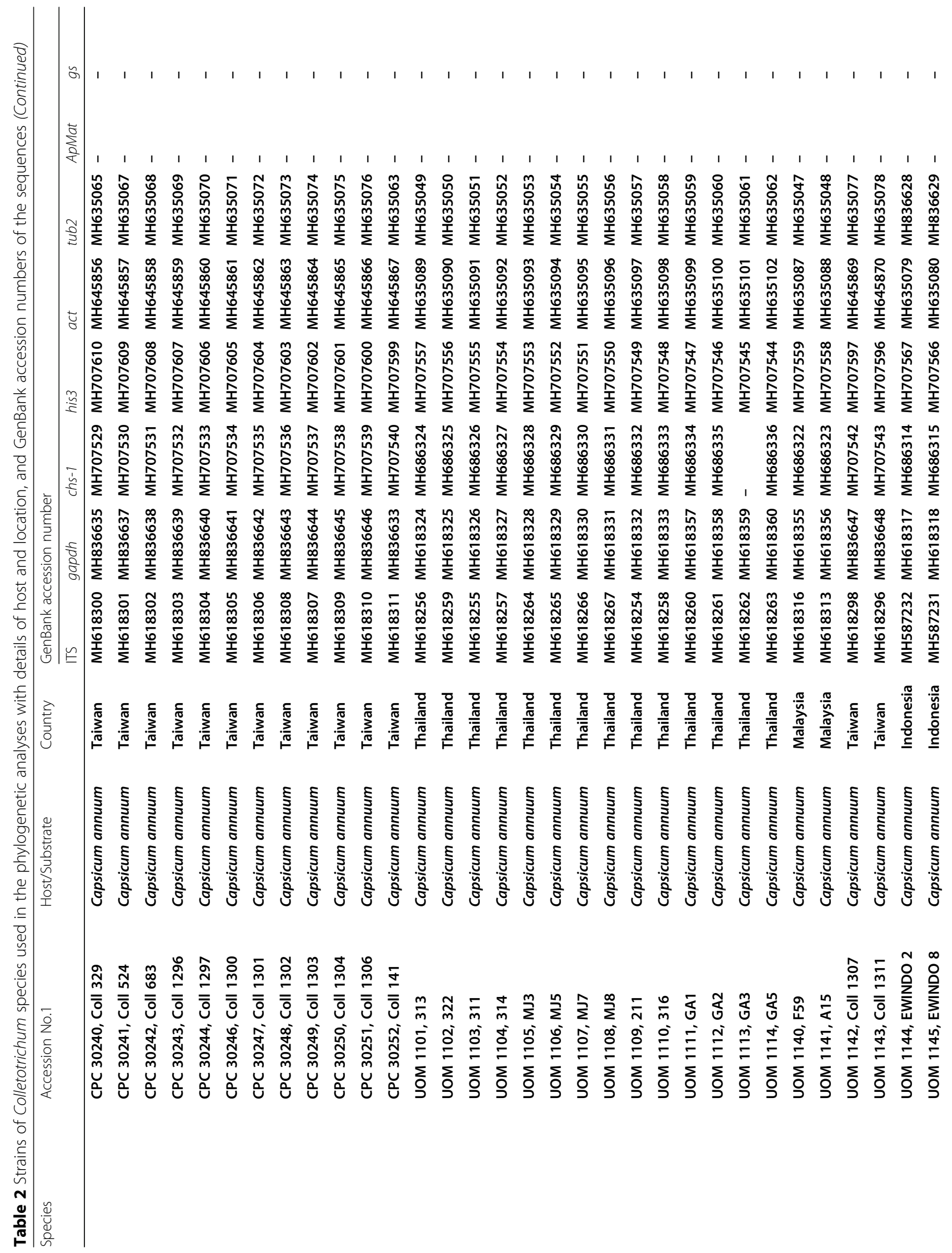




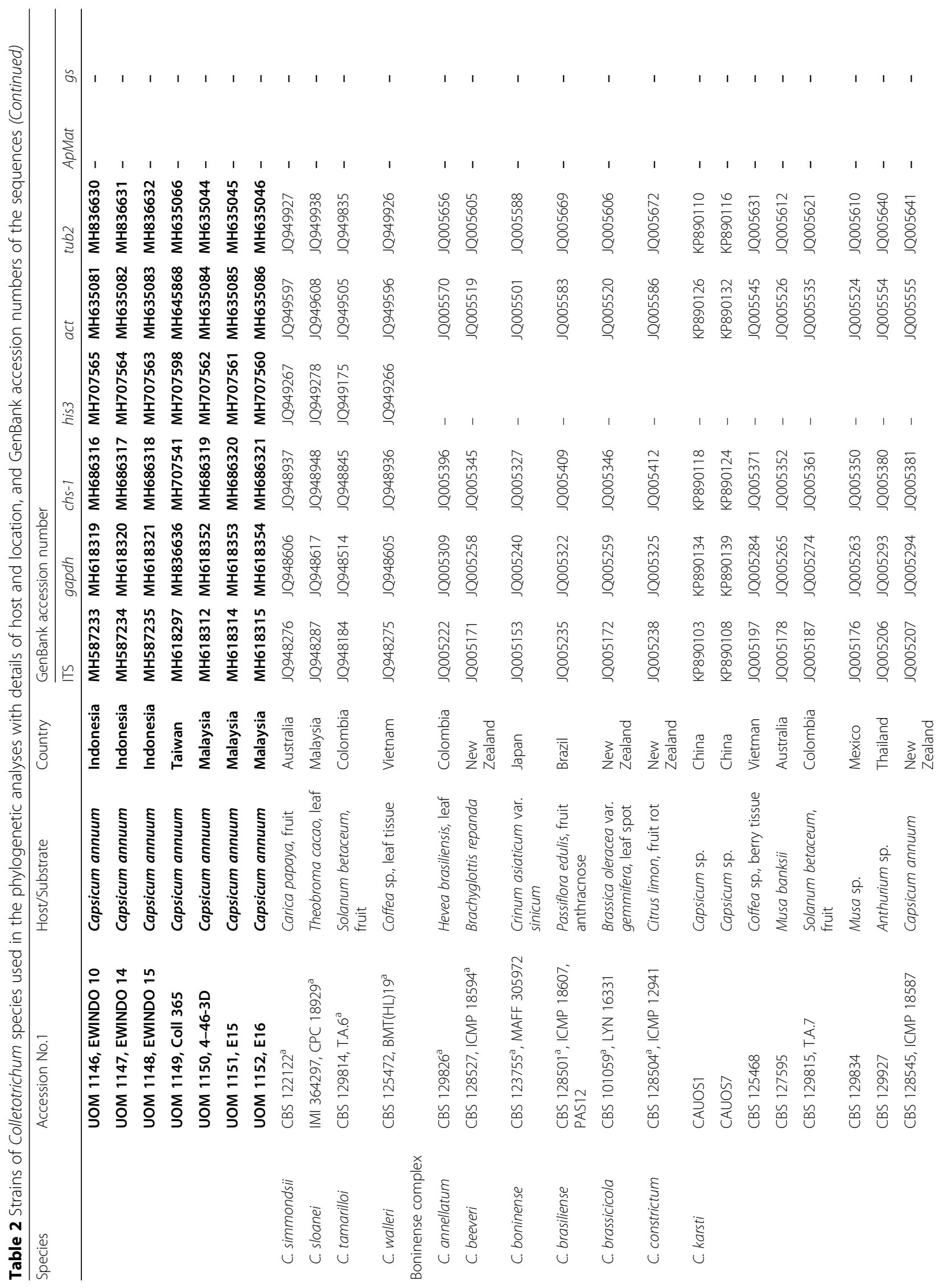




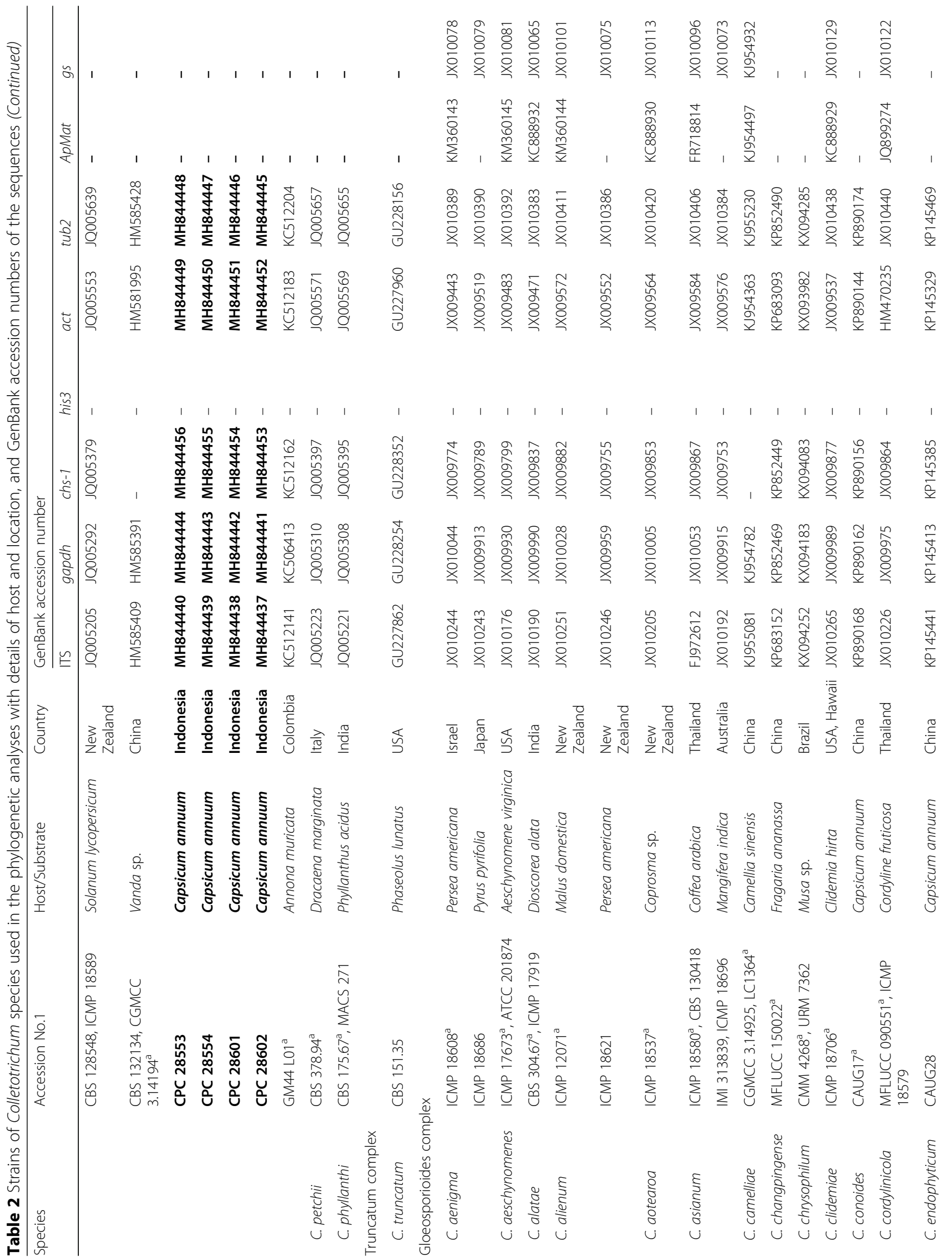




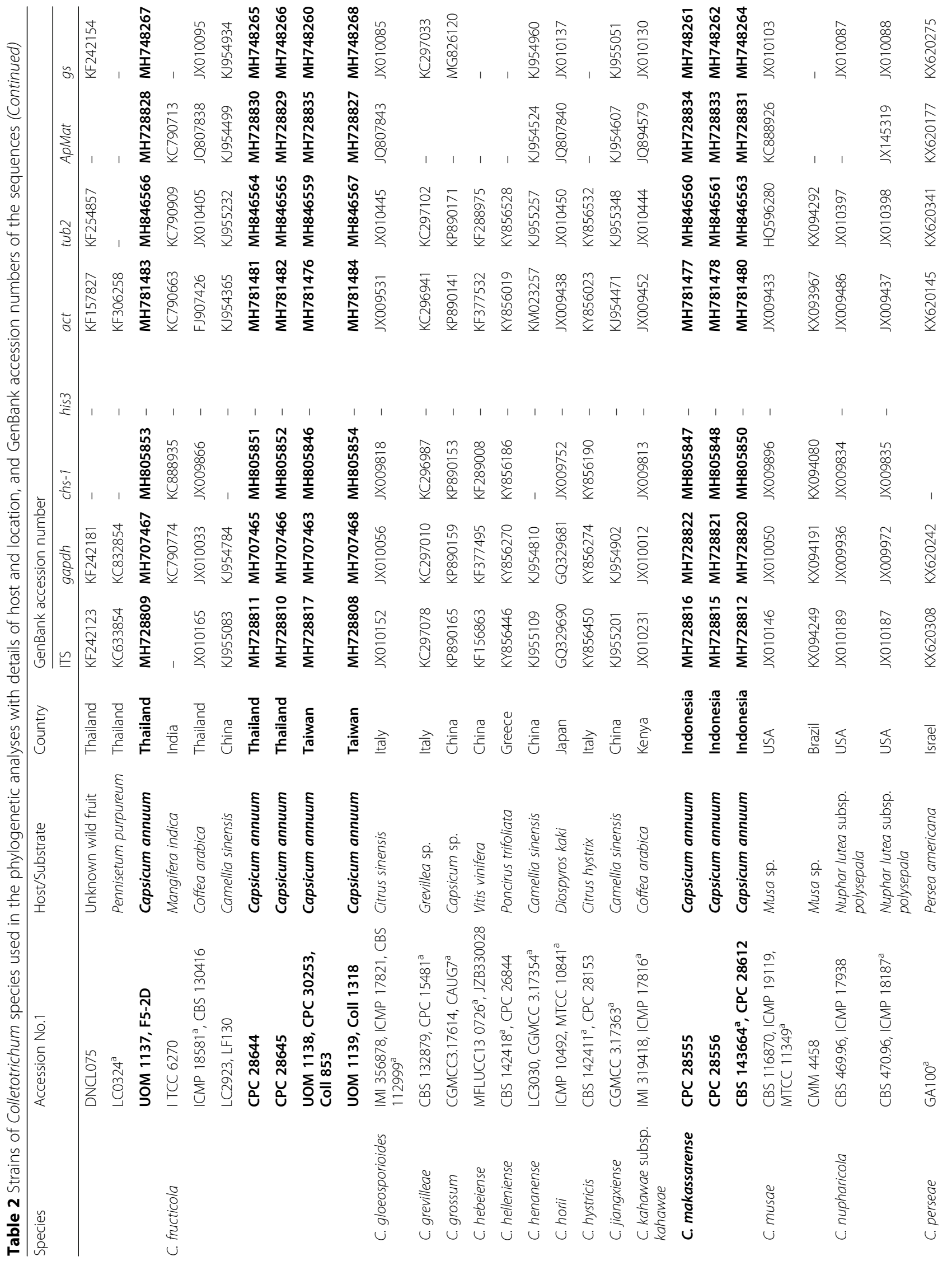




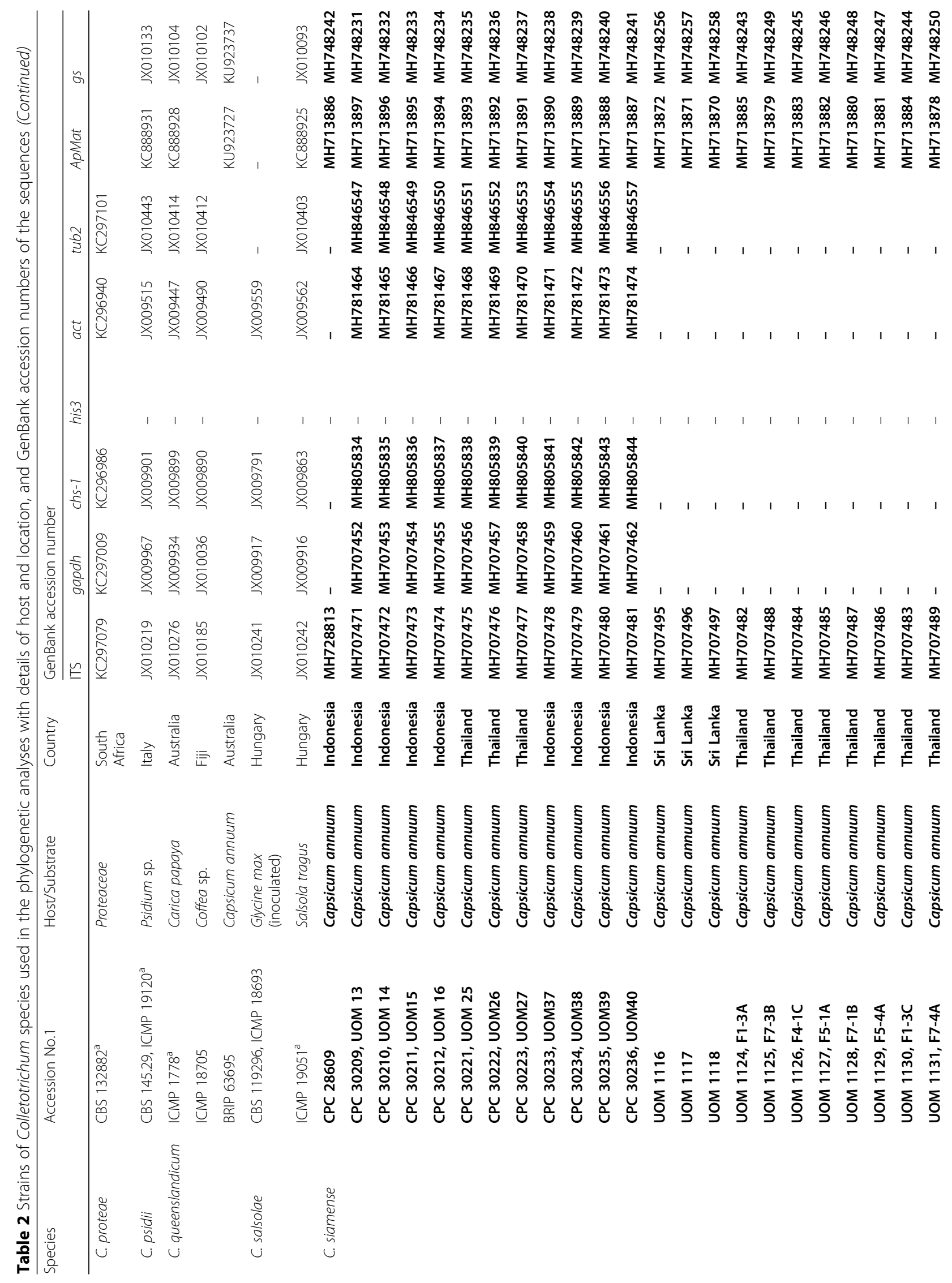




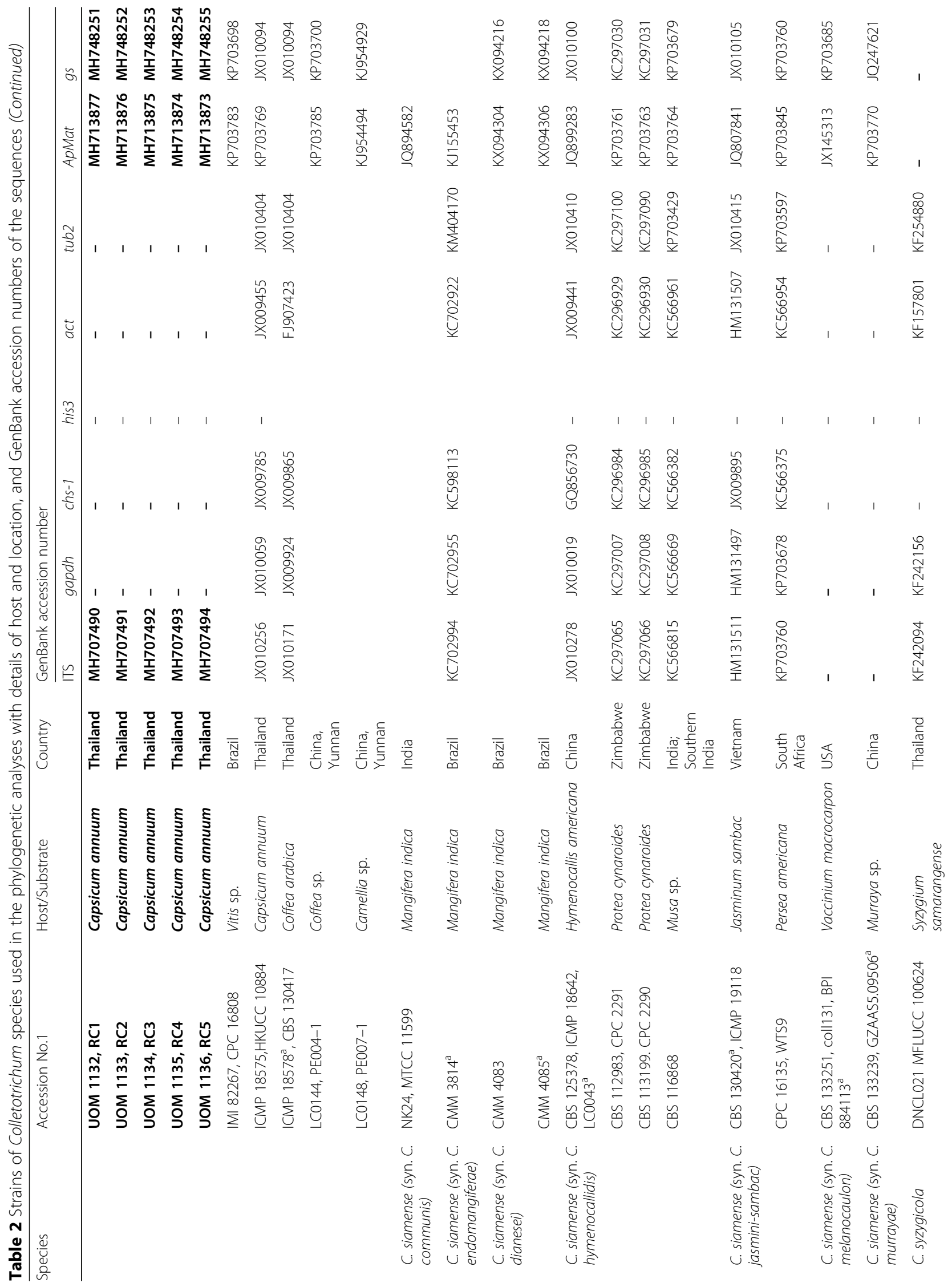




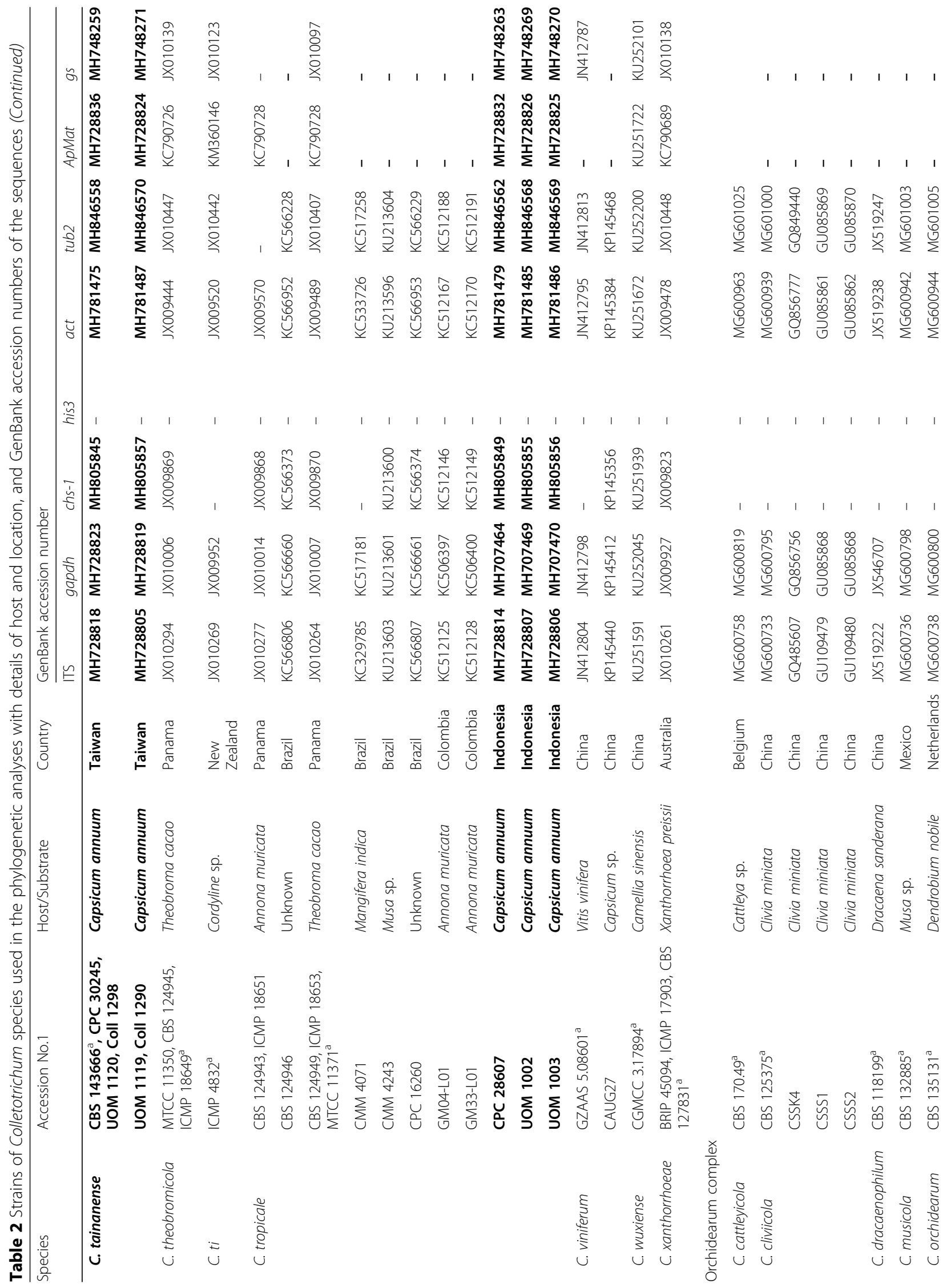




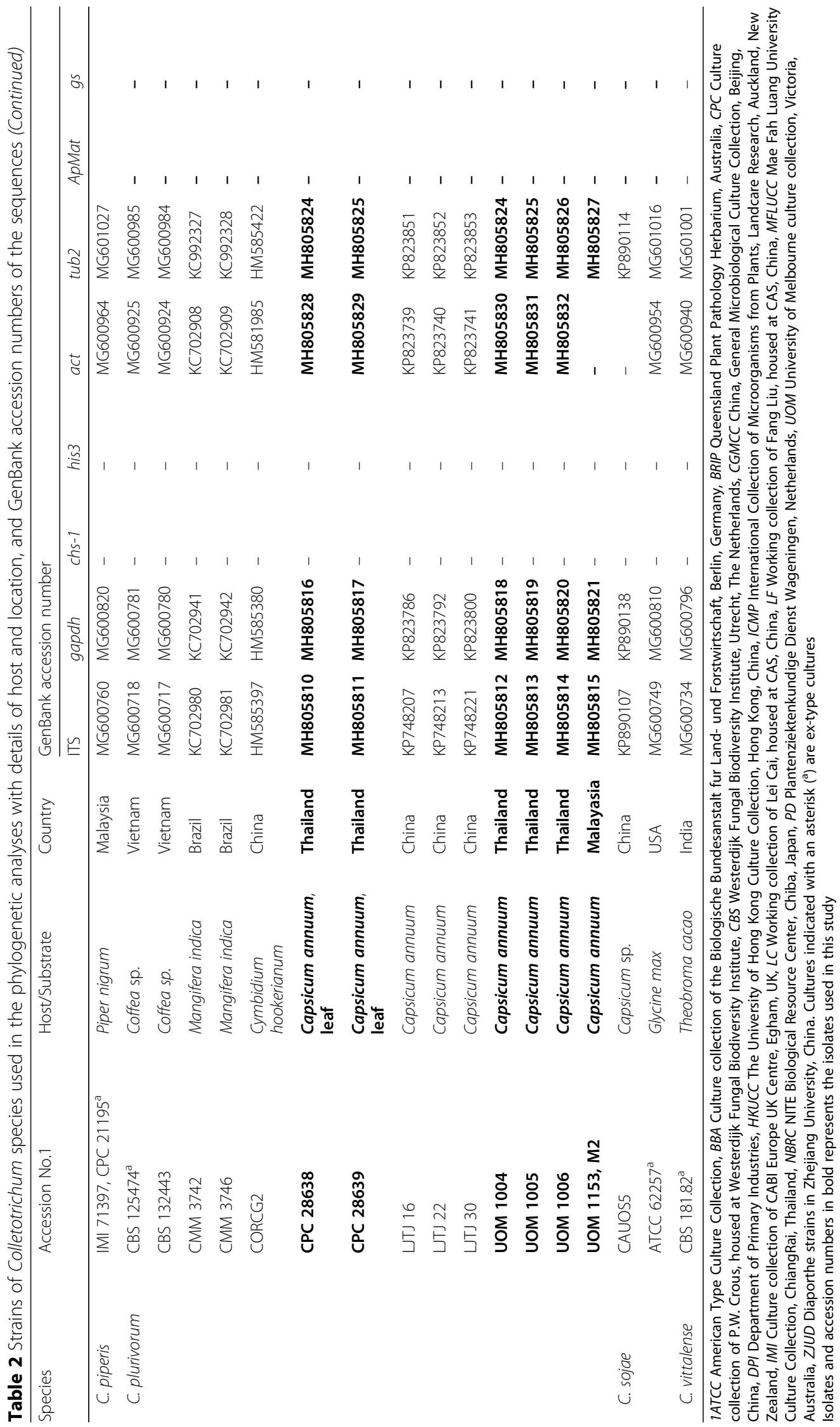




\section{Phylogenetic analyses}

Gene sequences of each isolate were examined using Geneious Pro v. 11.1.4, aligned by CLUSTALW2 (Larkin et al. 2007) and edited manually where necessary. ITS and $t u b 2$ sequences of selected isolates representing all the species complexes were analysed to determine to which clade each isolate belonged, and an initial phylogenetic tree was produced with a maximum likelihood analysis (ML) as implemented in MEGA v. 6 with 1000 bootstrap replicates (data not shown). For isolates from the acutatum complex, concatenated datasets were generated comprising ITS, chs-1, act, gapdh, his3 and tub2 gene sequences. For isolates from the gloeosporioides complex, two concatenated datasets were generated comprising ITS, chs-1, act, gapdh and tub2 gene sequences, and comprising ApMat and gs gene sequences. For isolates from the boninense and orchidearum complexes concatenated datasets were generated comprising ITS, gapdh, act and tub2 gene sequences. Selected reference or ex-type strains from each complex (Table 2) were included in the analyses (Damm et al. 2012b, 2019; Marin-Felix et al. 2017; Weir et al. 2012).

Further phylogenetic analyses were performed using MrBayes v. 3.2.6 (Ronquist et al. 2012) for Bayesian inference analyses (BI), and PAUP (Phylogenetic Analysis Using Parsimony) v. 4.0b10 (Swofford 2003) for parsimony analyses. For BI analyses, the best nucleotide substitution model for each locus was determined by MrModeltest v. 2.3 (Nylander 2004) (Table 3), and eight simultaneous MCMC chains were run for 1 bn generations. Trees were sampled every 100 generations for the acutatum, boninense and orchidearum complexes, and every 1000 generations for the gloeosporioides complex 2-gene alignment and every 10 generations for the gloeosporioides complex 5-gene alignment. The heating parameter was set to 0.2 and analyses stopped once the average standard deviation of split frequencies was below 0.01 . The first $25 \%$ of trees, representing the burn-in phase of the analyses, were discarded and the remaining trees in each analysis were used to calculate posterior probabilities. The generated $50 \%$ majority rule consensus tree was viewed in TreeView v. 1.6.6 (Page 1996). A maximum parsimony (MP) analysis was performed on the multilocus alignments as well as for each gene separately with PAUP v. 4.0b10 (Swofford 2003) using the heuristic search option with 100 random sequence additions and tree bisection and reconstruction (TBR) as the branch-swapping algorithm. Gaps were treated as new character states and missing data as missing characters. Bootstrap support values were calculated based on 1000 bootstrap replicates. Statistical measures calculated included tree length $(\mathrm{TL})$, consistency index $(\mathrm{CI})$, retention index (RI) and rescaled consistency index (RC) (Table 3). Alignments and tree files are deposited in TreeBASE (accession https://www.treebase.org/treebase-web/home. html; study S23829).

\section{Pathogenicity assay}

Pathogenicity tests on chili fruit were conducted using only Colletotrichum isolates with straight conidia as previous studies had extensively studied the pathogenicity of C. truncatum in chili (Mongkolporn et al. 2010, Ranathunge et al. 2012). There were 15 representative isolates of C. scovillei from Indonesia, Thailand and Taiwan, 10 isolates of $C$. siamense from Indonesia and Thailand, and one isolate each from the other eight species with straight conidia. Detached mature red chili fruits (Capsicum annuum genotype Bangchang) were used for the pathogenicity assay as described by De Silva et al. (2017a). Pathogenicity of each isolate was tested with both non-wound and wound inoculation methods. Three replicate fruits were tested per isolate while experiments were carried out three times.

Data were analysed using the Mixed Procedure in SAS v. 9.4 by fitting the linear mixed model:

$$
Y_{i j k l}=\mu+S_{i}+I_{j}\left(S_{i}\right)+R_{k}+R_{k} * S_{i}+R_{k} * I_{j}\left(S_{i}\right)+e_{i j k l}
$$

where $\mu$ is the grand mean, $S_{i}$ is the fixed species effect, and $R_{k}, R_{k}{ }^{*} S_{i}, R_{k}{ }^{*} I_{j}\left(S_{i}\right)$ and $e_{i j k l}$ are respectively the random effects of replicate, replicate by species interaction, replicate by isolate within species interaction, and error. Separate analyses were done for wound and non-wound data as preliminary analysis showed there was significant species by wound interaction. Least squared means were estimated for each species and t-test carried out between each pair of means.

\section{RESULTS}

\section{Isolates}

The Colletotrichum isolates with falcate conidia and ITS sequences matching to those of the ex-type of $C$. truncatum were the most common ( $n=115)$, representing $44 \%$ of all isolates. Colletotrichum truncatum was found in the collections from Indonesia, Malaysia, Sri Lanka and Thailand (Fig. 6). Colletotrichum truncatum isolates were not included in the collection from the World Vegetable Center in Taiwan as only the species with straight conidia were selected for identification. The remaining $56 \%$ of isolates $(n=145)$ were of species with straight conidia that mostly belonged to the acutatum and gloeosporioides complexes.

\section{Phylogenetic analyses Acutatum complex}

For the 69 isolates and 29 reference species in the acutatum complex, the phylogenetic analysis of the combined data sets using six genes (ITS, tub2, gapdh, chs-1, act 


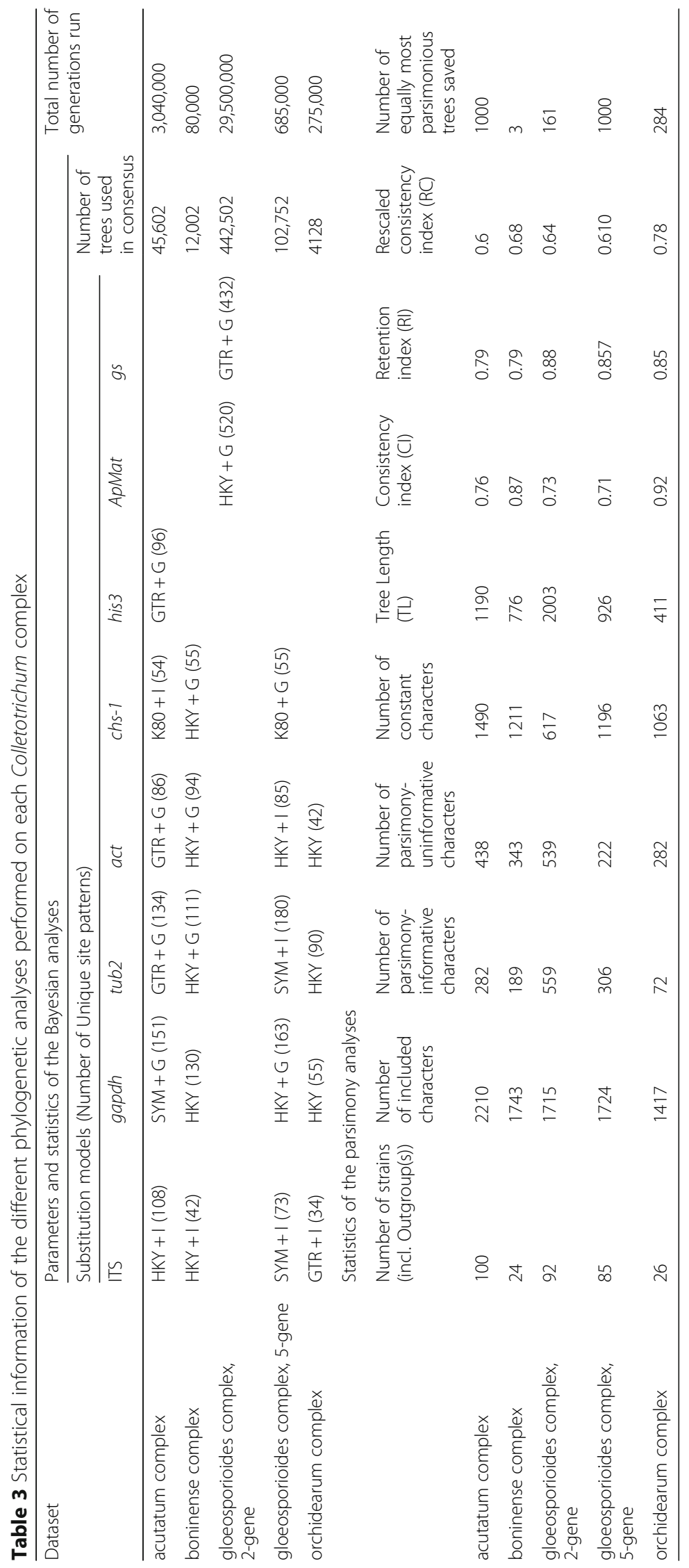


and his3) with C. boninense (CBS 123755) as the outgroup comprised 100 isolates including the outgroup and 2315 characters including the alignment gaps and excluded characters. The Bayesian analysis of this alignment, based on 629 unique site patterns (ITS: 108, tub2: 134, gapdh: 151, act: 86, chs-1: 54 and his3: 96) lasted $3,040,000$ generations, resulting in 60,802 total trees of which 45,602 trees were used to calculate the posterior probabilities. The parsimony analysis yielded the maximum of 1000 equally most parsimonious trees. Bootstrap support values of the MP analysis $(\mathrm{MP}>49 \%)$ and the $\mathrm{BI}$ posterior probabilities $(\mathrm{PP}>0.90)$ were plotted at the nodes (Fig. 1). Overall, the species clades recognised received similar support values, although the association between species did not always receive similar support, e.g. the node linking C. paranaense and C. melonis $(\mathrm{MP}<50 \%$ / $\mathrm{PP}=0.99)$. The phylogenetic analyses of the acutatum complex identified C. scovillei as the most prevalent species in Indonesia, Malaysia, Thailand and Taiwan. However, C. scovillei was not isolated from Sri

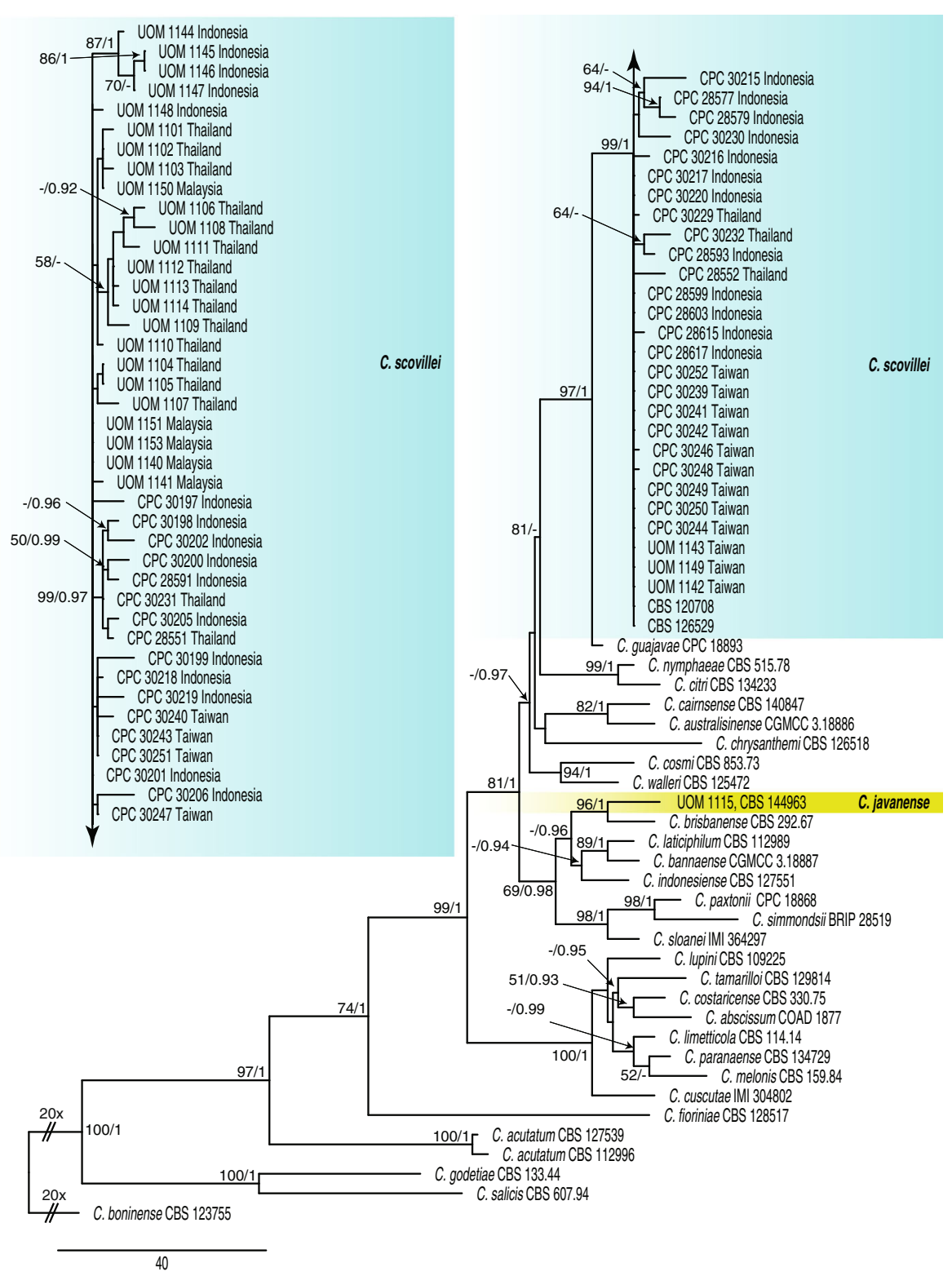

Fig. 1 First of 1000 equally most parsimonious trees obtained from a heuristic search of the combined ITS, tub2, gapdh, chs-1, his3 and act sequence alignment of the Colletotrichum isolates in the acutatum complex. The parsimony bootstrap support values (MP > 49\%) and Bayesian posterior probabilities ( $P P>0.90)$ are displayed at the nodes (MP/PP). The tree was rooted to C. boninense (CBS 123755). The bar indicates 40 changes. Coloured blocks are used to indicate clades containing isolates from chili 
Lanka. In addition, an isolate from Java in Indonesia (UOM 1115) clustered related to C. brisbanense (96\% BS/ 1 PP; Fig. 1).

\section{Boninense complex}

For the four isolates and 10 reference species in the boninense complex the phylogenetic analyses of the combined data sets using five genes (ITS, gapdh, tub2, act and chs-1) with C. truncatum (CBS 151.35) as the outgroup comprised 24 isolates and 1867 characters including the alignment gaps and excluded characters (Fig. 2). The Bayesian analysis of the combined alignment, based on 432 unique site patterns (ITS: 42, gapdh: 130, tub2: 111, act: 94 and chs-1: 55) lasted 80,000 generations, resulting in 16,002 total trees of which 12,002 trees were used to calculate the posterior probabilities. The parsimony analysis yielded three equally most parsimonious trees. Bootstrap support values of the MP analysis $(\mathrm{MP}>49 \%)$ and the $\mathrm{BI}$ posterior probabilities ( $\mathrm{PP}>0.90$ ) were plotted at the nodes (Fig. 2). Overall, the nodes received similar support values, except for the subclustering of strains CBS 128545, CBS 128548 and CBS 129927 in the C. karsti clade (MP 67\% / PP = 0.98). The phylogenetic analyses of the boninense complex identified the most prevalent species as C. karsti occurring only in Indonesia.

\section{Gloeosporioides complex}

For the 42 isolates and the 41 reference species in the gloeosporioides complex, two phylogenetic trees were constructed, one from the ApMat and gs sequence alignment and the second from the ITS, gapdh, act, tub2, chs-1 sequence alignment (Figs. 3 and 4). The analyses using the 5-gene alignment with $C$. theobromicola CBS 124945 as the outgroup (Fig. 4) comprised 85 isolates including the outgroup and 1863 characters including the alignment gaps and excluded characters. The Bayesian analysis of the combined alignment, based on 556 unique site patterns (ITS: 73, gapdh: 163, act: 85, tub2: 180, chs-1: 55) lasted 685,000 generations, resulting in 137,002 total trees of which 102,752 trees were used to calculate the posterior probabilities. The parsimony

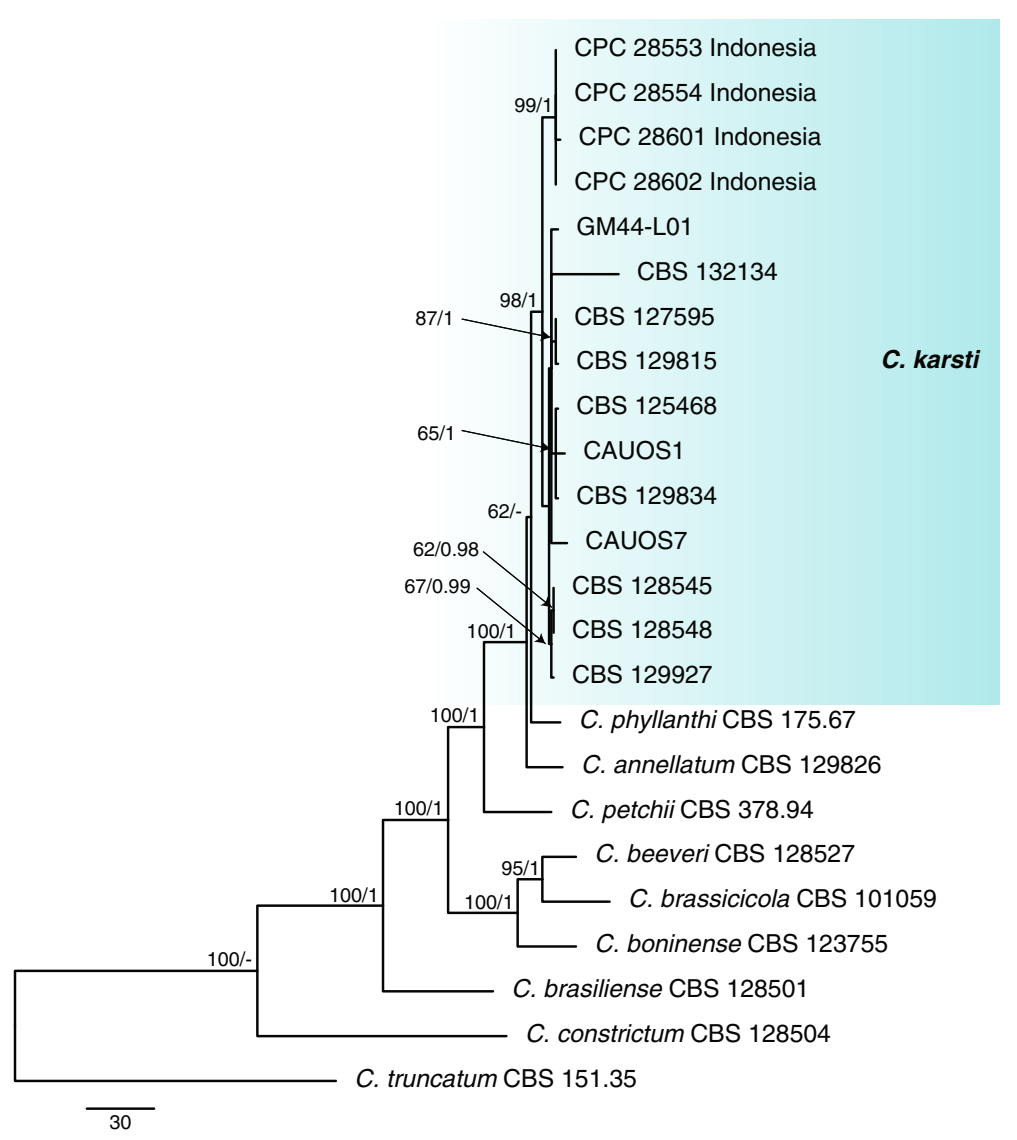

Fig. 2 First of three equally most parsimonious trees obtained from a heuristic search of the combined ITS, tub2, gapdh, chs-1 sequence alignment of the Colletotrichum isolates in the boninense complex. The parsimony bootstrap support values (MP $>49 \%)$ and Bayesian posterior probabilities (PP > 0.90) are displayed at the nodes (MP/PP). The tree was rooted to C. truncatum (CBS 151.35). The bar indicates 30 changes. Coloured blocks are used to indicate clades containing isolates from chili 


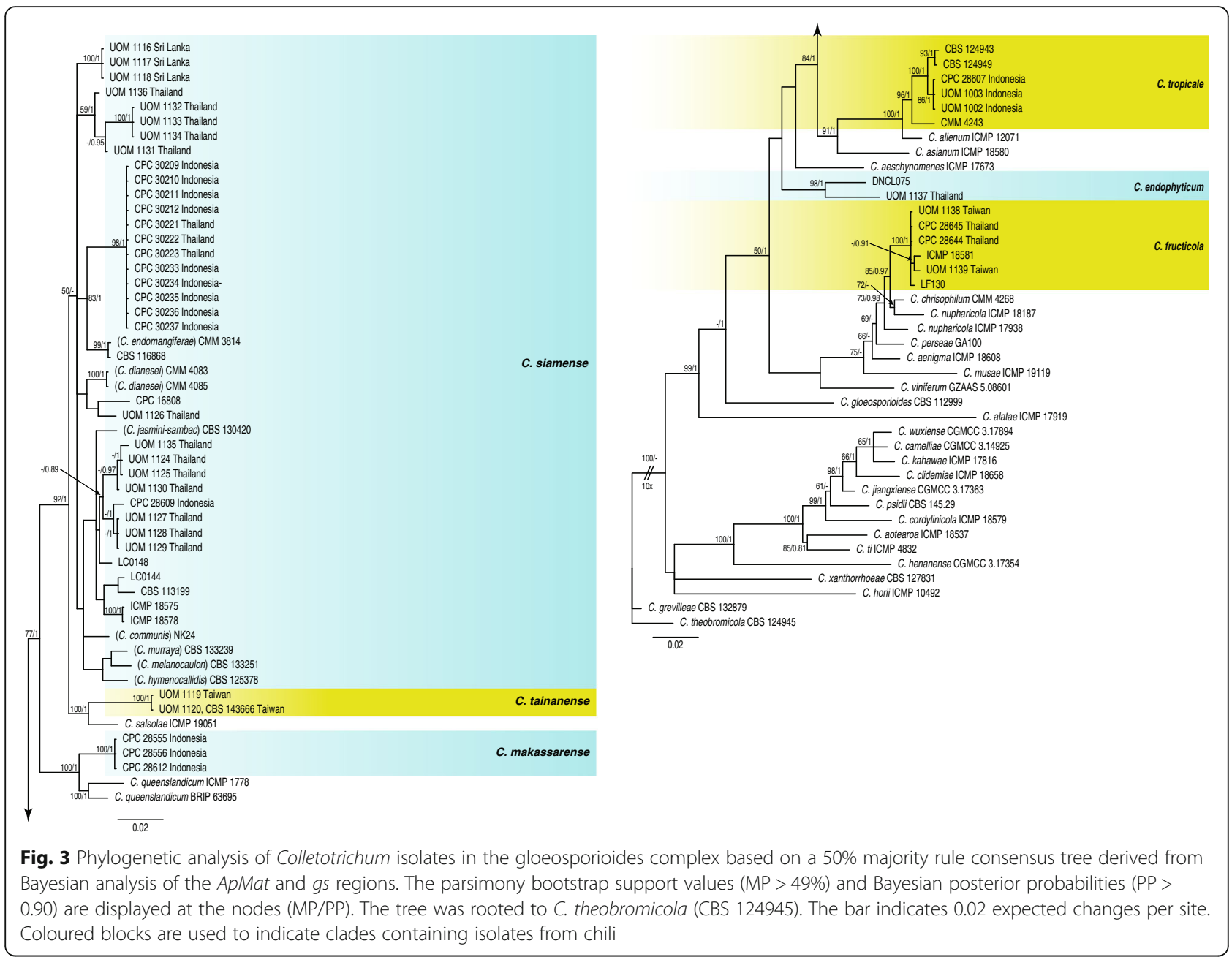

analysis yielded the maximum of 1000 equally most parsimonious trees. Bootstrap support values of the MP analysis $(\mathrm{MP}>49 \%)$ and the BI posterior probabilities ( $\mathrm{PP}>0.90)$ were plotted at the nodes (Fig. 4). Overall, the species clades recognised in this study received similar support values, except for the $C$. siamense clade $(\mathrm{MP}<50 \% / \mathrm{PP}<0.91)$ and the C. fructicola clade (MP $57 \% / \mathrm{PP}=0.99)$.

The analysis using the ApMat and gs sequence alignment comprised of 92 isolates with $C$. theobromicola CBS 124945 as the outgroup (Fig. 3) and 1824 characters including the alignment gaps and excluded characters. The Bayesian analysis of the combined alignment, based on 952 unique site patterns (ApMat: 520, gs: 432) lasted $29,500,000$ generations, resulting in 590,002 total trees, of which 442,502 trees were used to calculate the posterior probabilities. The parsimony analysis yielded 161 equally most parsimonious trees. Bootstrap support values of the MP analysis ( $\mathrm{MP}>49 \%)$ and the BI posterior probabilities ( $\mathrm{PP}>0.90$ ) were plotted at the nodes (Fig. 3). Overall, the species clades recognised in this study received similar support values, except for the $C$. siamense clade $(\mathrm{MP}=$ 92\% / PP < 0.91).

Phylogenetic analyses of the gloeosporioides species complex identified 69\% (29) of the chili fruit isolates as C. siamense. In the 2-gene tree a distinct subclade within the $C$. siamense clade formed with $100 \%$ bootstrap support which contained isolates from Chiang Mai in Thailand, and Gowa and Jeneponto in South Sulawesi of Indonesia (Fig. 3). These isolates from Indonesia and Thailand had very distinct sequences compared to the ex-type reference $C$. siamense strain (CBS 130417) with $28 \mathrm{bp}$ difference in the $g s$ gene and $25 \mathrm{bp}$ difference in the ApMat gene. A significant sub-clade formed within C. siamense with full (100\% BS/1 PP) support values in the 2-gene tree. The same isolates in the 5-gene tree did not show the same level of difference but showed a strong similarity between the $C$. siamense isolates. In the 2 -gene tree there were also significant subclades of isolates associated with different geographical regions, in 


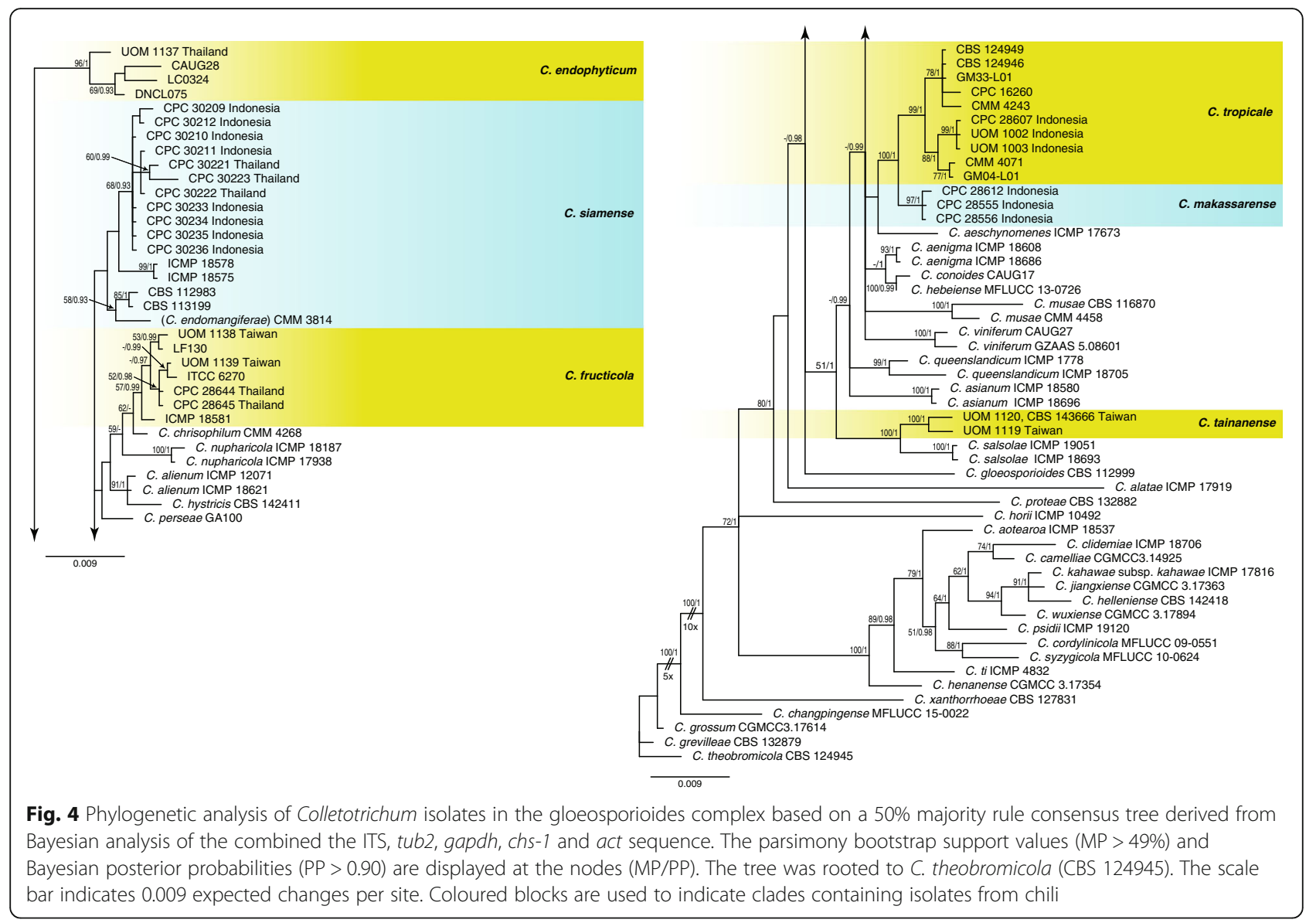

particular the distinct subclade of the Sri Lankan isolates (UOM 1116, UOM 1117, UOM 1118) from Kandy and the separate subclade of Thai isolates from Ratchaburi (UOM 1132, UOM 1133, UOM 1134).

Other species identified in the gloeosporioides complex included $C$. endophyticum and C. fructicola from Thailand, C. fructicola and C. tainanense sp. nov. from Taiwan, and C. tropicale and C. makassarense sp. nov. from Indonesia. Most of the identified species including the two new species were supported in distinct clades with significant bootstrap values in both the 5-gene and 2-gene trees (Figs. 3 and 4). However, due to a lack of sequence data of the ApMat gene for some reference strains, it was difficult to provide a good support for placement of some species such as $C$. endophyticum in the 2-gene trees. Three isolates (CPC 28607, UOM 1002, UOM 1003) collected from the Makassar region in Indonesia showed a close relationship to the reference species $C$. tropicale in the ApMat and gs tree (Fig. 3). Individual gene trees of ITS, act, tub2, chs-1 loci (data not shown) also supported these isolates as C. tropicale. Nevertheless, in the 5-gene tree a separate sub clade was formed with full support (100\% BS/1 PP) different to the $C$. tropicale reference species (Fig. 4). In both trees, two isolates (UOM 1120, UOM 1119) collected from Tainan in Taiwan formed a significant distinct clade with full support (100\% BS/1 PP) separate from C. salsolae.

\section{Orchidearum complex}

For the six isolates and nine reference species in the orchidearum complex the phylogenetic analysis of the combined data sets using four genes (ITS, gapdh, tub2 and $a c t$ ) with $C$ dracaenophilum (CBS 118199) as the outgroup comprised 26 isolates and 1543 characters including the alignment gaps and excluded characters. The Bayesian analysis of the combined alignment, based on 221 unique site patterns (ITS: 34 , gapdh: 55 , act: 42 , tub2: 90) lasted 275,000 generations, resulting in 5502 total trees of which 4128 trees were used to calculate the posterior probabilities. The parsimony analysis yielded 284 equally most parsimonious trees. Bootstrap support values of the MP analysis (MP $>49 \%)$ and the BI posterior probabilities $(\mathrm{PP}>0.90)$ were plotted at the nodes (Fig. 5). Overall, the species clades recognised in this study received similar support values, except for the $C$. plurivorum clade $(\mathrm{MP}=64 \% / \mathrm{PP}<1)$ and the C. cliviicola clade $(\mathrm{MP}=87 \% / \mathrm{PP}<1)$. 


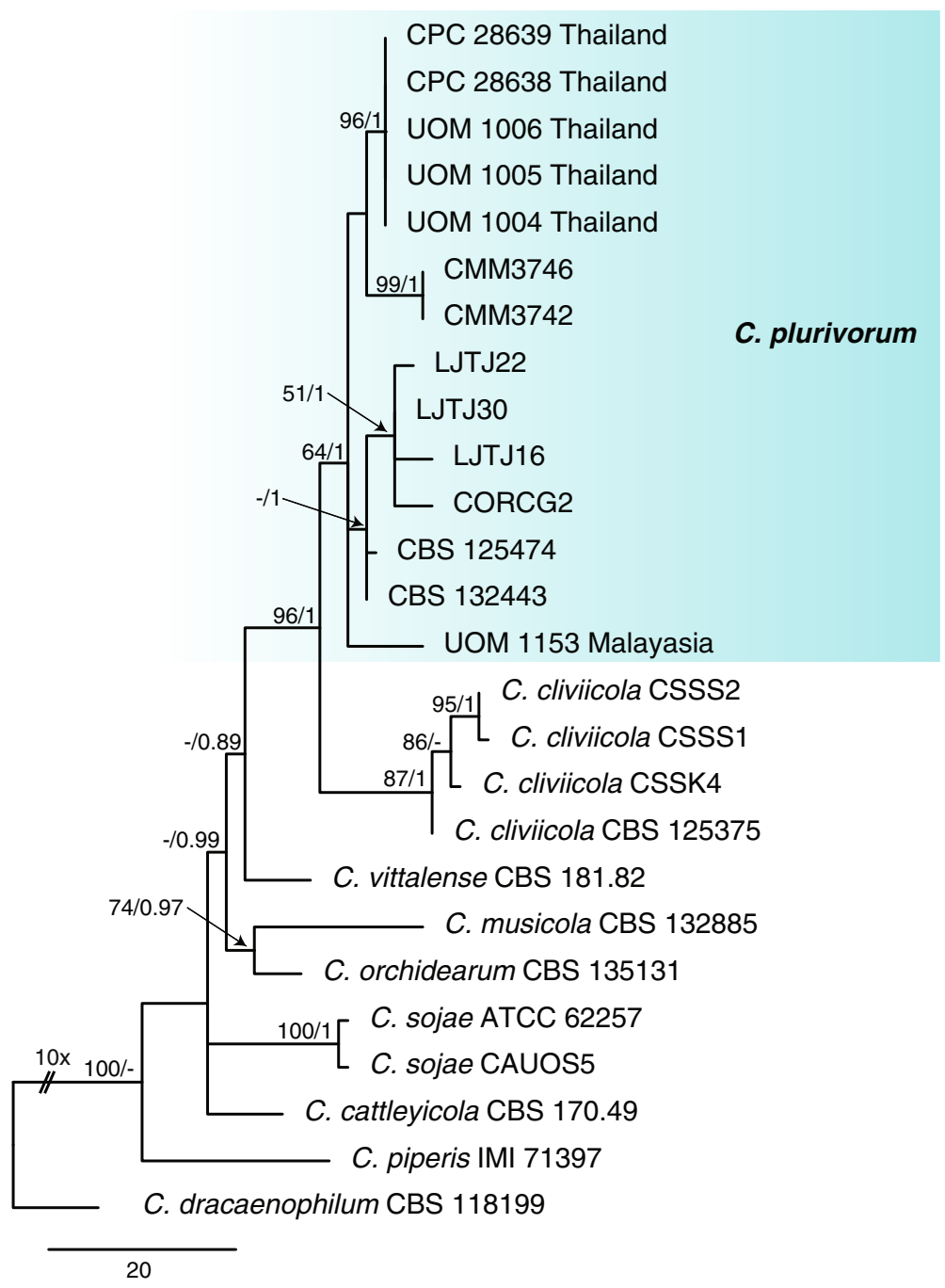

Fig. 5 First of 284 equally most parsimonious trees obtained from a heuristic search of the combined ITS, tub2, gapdh, chs-1, and act sequence alignment of the Colletotrichum isolates in the orchidearum complex. The parsimony bootstrap support values (MP > 49\%) and Bayesian posterior probabilities (PP > 0.90) are displayed at the nodes (MP/PP). The tree was rooted to C. dracaenophilum (CBS 118199). The scale bar indicates 20 changes. Coloured blocks are used to indicate clades containing isolates from chili

The phylogenetic analyses identified the isolates from Thailand and Malaysia as C. plurivorum. Five isolates collected from Thailand, including three taken from infected chili leaves from Chiang Rai and another two isolates collected from infected green chili fruit from Bangkok, formed a poorly supported subclade within $C$. plurivorum (Fig. 5).

\section{TAXONOMY}

Morphological observations and phylogenetic data of the straight conidia species clearly identified three novel species, two from Indonesia and one from Taiwan. Detailed morphological descriptions are provided below for all the Colletotrichum species associated with chili anthracnose (Table 4).

\section{Colletotrichum javanense D.D. De Silva, P.W. Crous \&} P.W.J. Taylor, sp. nov. MycoBank MB826936.

Figure 6 Etymology: Named after Java, the island in Indonesia where the species was collected.

Diagnosis: Colletotrichum javanense differs from C. brisbanense in forming distinct chlamydospores and acervular conidiomata on all the media tested. In contrast, C. brisbanense only produced Conidiomata on Anthriscus stem, but no basal cells observed. In addition, $C$. javanense grows faster than $C$. brisbanense (C. javanense on OA, MEA and SNA 60, 55 and $66 \mathrm{~mm}$ diam in $7 \mathrm{~d}$, respectively, C. brisbanense on OA and SNA 18.5, $20 \mathrm{~mm}$ diam in $7 \mathrm{~d}$, respectively). Colletotrichum 
Table 4 Morphological characteristics of Colletotrichum species causing anthracnose of chili

\begin{tabular}{lllll}
\hline Species & Conidiogenous cells length $(\mu \mathrm{m})$ & Conidia length $(\mu \mathrm{m})$ & Conidia width $(\mu \mathrm{m})$ & Appressoria $(\mu \mathrm{m})$ \\
\hline C. endophyticum & $12-21 \times 3-4$ & $(10.4-) 12.5-13(-14.5)$ & $(3-) 4.5-5(-6.3)$ & $(10.5-) 12(-15) \times(3-) 4.5(-10)$ \\
C. fructicola & $7-17.5$ & $(10.5-) 12.5-13(-18.5)$ & $(3-) 4-5.5(-6.5)$ & - \\
C. javanense & $7-17.5$ & $(11.5-) 13.5-14(-15.8)$ & $(2.4-) 3.5-4(-4.3)$ & $(6-) 8.2(-11.3) \times(4.2-) 5.6(-7.5)$ \\
C. karsti & - & $(11.6-) 12.5-13(-15.7)$ & $(3-) 4-5.2(-6.5)$ & $6-12.5 \times 3.5-8.2$ \\
C. makassarense & $7-25 \times 3-4$ & $(11-) 13-15(-17)$ & $(4-) 4.5-5$ & $(6-) 8(-10.5) \times(4-) 3.5(-8.6)$ \\
C. plurivorum & $26-48 \times 3-4$ & $(13.7-) 14-16(-18.3)$ & $(3.8-) 5(-5.6)$ & $(10.5-) 12(-23) \times(3.5-) 5.5(-11.5)$ \\
C. scovillei & $7-17.5$ & $(5.5-) 9.5-10(-12)$ & $(2.4-) 3(-3.8)$ & $(4-) 5.5(-12.5) \times(3.5-) 4.5-5(-6.5)$ \\
C. siamense & $6.5-16$ & $(13-) 14(-15.5)$ & $(3-) 4.2(-5.3)$ & $(4.5-) 7.5(-10) \times(3.5-) 3(-5.5)$ \\
C. tainanense & - & $(16-) 17-18(-22)$ & $(4.5-) 5$ & $(6.5-) 10.3(-14.3) \times(6.2-) 5.2(-9.5)$ \\
C. tropicale & $7-15 \times 3.5-4.5$ & $(13-) 14-16(-17)$ & $(3.5-) 4-5(-6)$ & - \\
\hline
\end{tabular}

javanense is phylogenetically distinct to C. brisbanense with both species being different in the sequences of chs-1, and most effectively with gapdh (7 bp difference) and his3 (4 bp difference).

Type: Indonesia: West Java, Purwakata regency, on fruit of Capsicum annuum, Dec. 2014, F. Fitriyah (CBS
H-144963 - holotype; CBS $144963=$ UOM $1115=$ EWINDO 3 - ex-type cultures).

Description: Sexual morph not observed. Asexual morph on PDA. Vegetative mycelium 1-5 $\mu \mathrm{m}$ diam, hyaline, smooth-walled, septate, branched hyphae. Chlamydospores globose or elongate, pale brown, smooth-walled, 5-
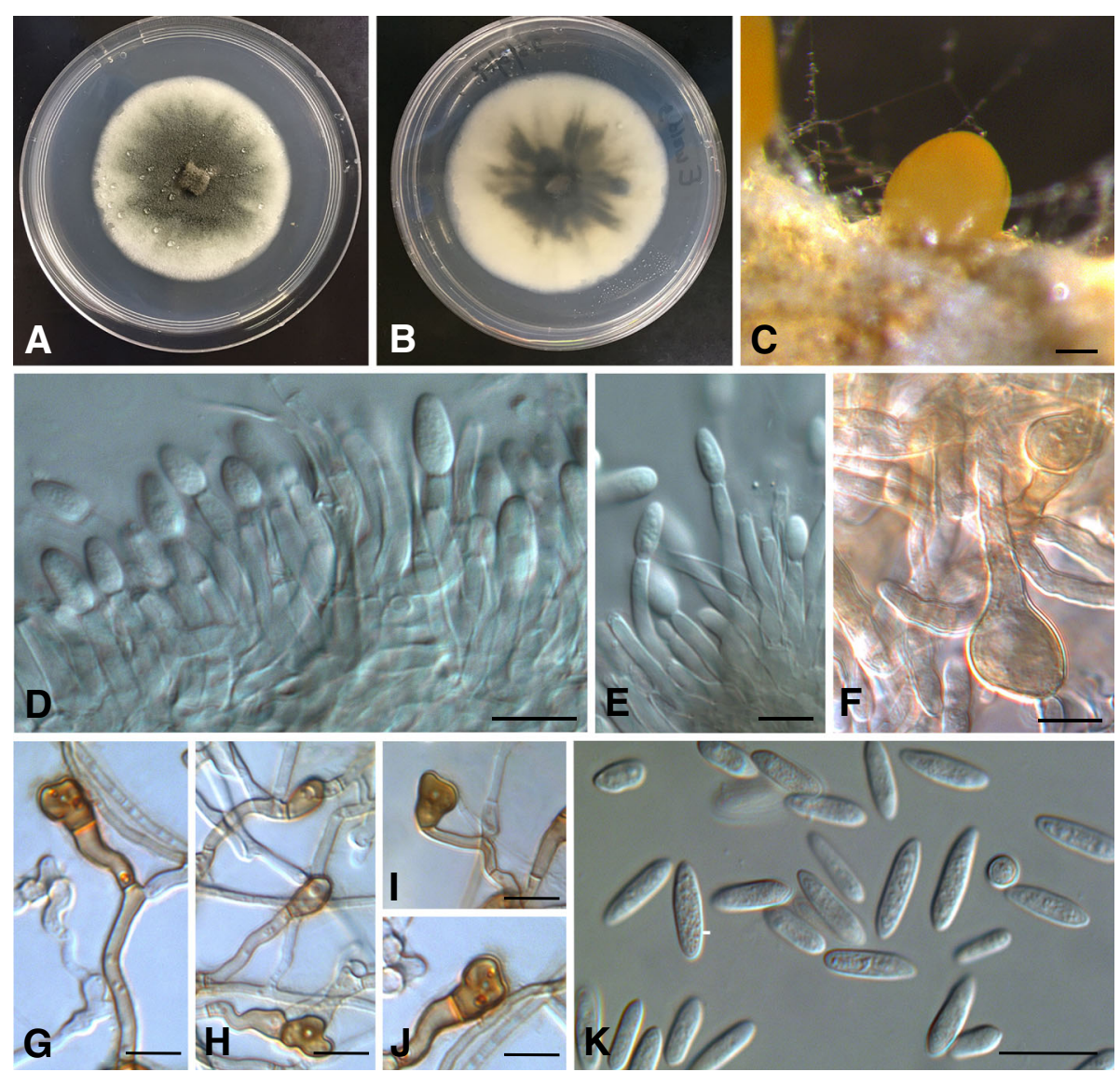

Fig. 6 Colletotrichum javanense (CBS 144963). a Colony on PDA. b Reverse side of the colony on PDA. c Conidioma on PDA. d-e Conidiophores and conidia. $\mathbf{f}$ Chlamydospores. $\mathbf{g}-\mathbf{j}$ Appressoria. $\mathbf{k}$ Conidia. Bars $=10 \mu \mathrm{m}$ 
$25 \times 3-8 \mu \mathrm{m}$. Conidiomata acervular, setae not observed. Conidiophores hyaline, septate, branched. Conidiogenous cells hyaline, cylindrical or ampulliform, 7-17.5 $\mu \mathrm{m}$, apex 1-3 $\mu \mathrm{m}$ diam. Conidia hyaline, aseptate, smooth-walled, mostly fusiform, one end rounded, the other end acute, or both ends acute (11.5-)13.5-14(-16) ×(2.5-) 4(-4.5) $\mu \mathrm{m}$. Conidia in mass yellow to orange colour. Appressoria single or in loose groups, medium brown, smooth-walled, subglobose or elliptical, with entire or undulate margin, $(6-) 8(-11.5) \times(4-) 6(-7.5) \mu \mathrm{m}$.

Asexual morph on SNA. Vegetative mycelium 1-7 $\mu \mathrm{m}$ diam, hyaline, smooth-walled, septate, branched hyphae. Chlamydospores globose or elongate, pale brown, smooth-walled, 4.5-28 $\times 4-8 \mu \mathrm{m}$. Conidiomata acervular, setae not observed. Conidiophores hyaline, septate, branched, 20-35 $\mu \mathrm{m}$ long. Conidiogenous cells hyaline, cylindrical or ampulliform, 5-20 $\mu \mathrm{m}$, apex, 1-3 $\mu \mathrm{m}$ diam. Conidia hyaline, aseptate, smooth-walled, cylindrical with both ends acute or one end round and one end acute, $(13.5-) 16.5(-24) \times(2.5-) 3(-4.5) \mu \mathrm{m}$. Conidia in mass with yellow to orange colour.

Culture characteristics: Colonies on PDA $48-54 \mathrm{~mm}$ diam in $7 \mathrm{~d}(6.5-7.5 \mathrm{~mm} / \mathrm{d})$, flat with entire margin; surface covered with grey to olive-green short aerial mycelium, margin white to light grey, reverse mostly cream whitish, olivaceous grey to black in the centre. Yellow to orange acervular conidiomata. Colonies on SNA were $60-66 \mathrm{~mm}$ diam in $7 \mathrm{~d}(8-9.5$ $\mathrm{mm} / \mathrm{d}$ ), flat with entire margin, hyaline to pale brown, surface covered with short grey aerial mycelium, reverse same colours. Orange acervular conidiomata at the centre of the culture. Colonies on OA were $55-60 \mathrm{~mm}$ diam in $7 \mathrm{~d}(7.8-8.5 \mathrm{~mm} / \mathrm{d})$, flat with entire margin; surface covered with cream to grey short aerial mycelium, margin white, reverse mostly light orange, with brown pigments. Orange acervular conidiomata. Colonies on MEA surface pale grey short aerial mycelium, reverse light orange.

Notes: The closest match in a blastn search with the gapdh sequence was GenBank JQ948617, C. sloanei strain IMI 364297 with $98 \%$ identity (4 bp differences), while the closest matches with the his3 sequence with 99\% identity (2 bp differences) were GenBank JQ949279 C. indonesiense strain CBS 127551 and GenBank KJ947248 C. guajavae isolate OBP19.
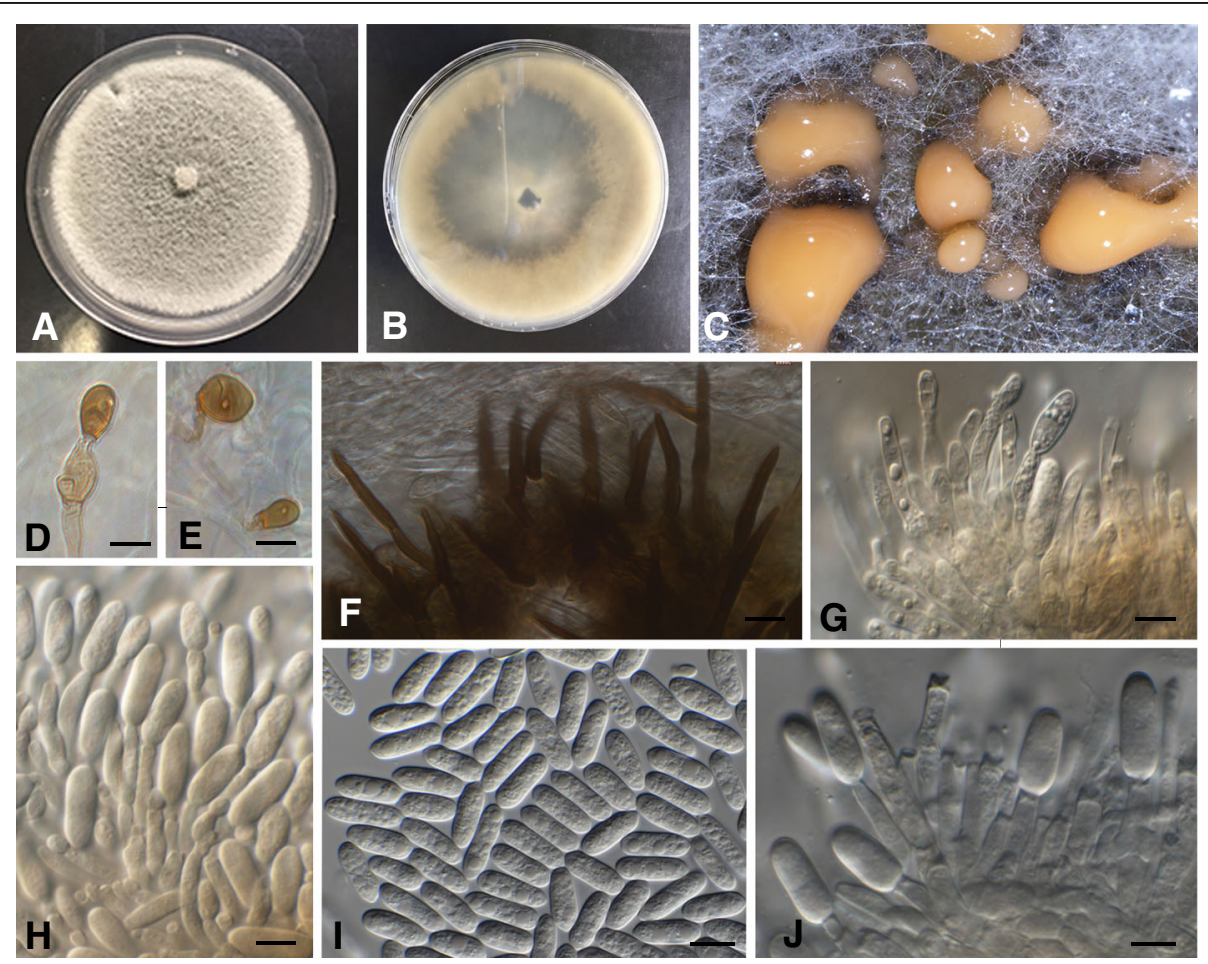

Fig. 7 Colletotrichum makassarense (CBS 143664). a Colony on PDA. b Reverse side of the colony on PDA. c Conidiomata. d-e Appressoria. f Setae, $\mathbf{g}, \mathbf{h}, \mathbf{j}$ Conidiophores and conidia. $\mathbf{i}$ Conidia. Bars $=10 \mu \mathrm{m}$ 
Colletotrichum makassarense D.D. De Silva, P.W. Crous \& P.W.J. Taylor, sp. nov. MycoBank MB827691.

Figure 7 Etymology: Named after Makassar, the city in South Sulawesi, Indonesia, where the species was collected.

Diagnosis: Colletotrichum makassarense is phylogenetically closely related to $C$. tropicale. Sequence data from ITS could not separate the two species, but they can be distinguished by all other genes tested and most effectively using ApMat (22 bp differences) and $g s$ (18 bp differences) sequence data.

Type: Indonesia: Makassar, from fruit lesion of Capsicum annuum, 7 Jun. 2015, P.W.J. Taylor E A. Nasruddin (CBS H-143664 - holotype; CBS 143664 = CPC $28612-$ ex-type cultures).

Description: Sexual morph not observed. Asexual morph on OA. Vegetative mycelium consisting of hyaline, smooth-walled, septate, branched hyphae, 2-3 $\mu \mathrm{m}$ diam. Chlamydospores not observed. Setae present, medium brown, 40-55 × 3-5 $\mu \mathrm{m}, 2-3$-septate, tapering to acute apices. Conidiomata acervular, 100-200 $\mu \mathrm{m}$ diam, with orange conidial masses. Conidiophores subcylindrical, flexuous, 1-4-septate, hyaline, smooth, branched, 15$45 \times 3-4 \mu \mathrm{m}$. Conidiogenous cells subcylindrical, hyaline, smooth, phialidic with periclinal thickening, 7-25 ×3$4 \mu \mathrm{m}$. Conidia hyaline, smooth, aseptate, subcylindrical, straight, apex obtuse, tapering at base to protruding truncate hilum, $1 \mu \mathrm{m}$ diam, prominently guttulate, (11-)13$15(-17) \times(4-) 4.5-5 \mu \mathrm{m}$. Appressoria solitary, medium brown, smooth-walled, subglobose, ellipsoidal to obovate, entire margin, (6-)8.0(-10.5) × (4-)3.5(-8.5) $\mu \mathrm{m}$.

Culture characteristics: Colonies on PDA $45 \mathrm{~mm}$ diam after $7 \mathrm{~d}(6.5 \mathrm{~mm} / \mathrm{d})$, colonies flat, with moderate aerial mycelium, on OA surface smoke-grey. On PDA surface smoke-grey, reverse olivaceous grey. On MEA surface dirty white, reverse ochreous.

Notes: The closest match in a blastn search with the ApMat sequence was GenBank KU923732, C. queenslandicum strain AUS22 with a 98\% identity (16 bp differences), while the closest match with the gs sequence with 99\% identity (7 bp differences) was GenBank KJ947286 C. siamense isolate OBP24. The best matches with the gapdh sequence were GenBank KX578784 C. siamense (99\% identity, 3 bp differences) and GenBank KU221347 C. queenslandicum (99\%, identity, 3 bp differences).

\section{Colletotrichum tainanense D.D. De Silva, P.W. Crous \& P.W.J. Taylor, sp. nov. MycoBank MB827692.}

Figure 8 Etymology: Named after Tainan, the city in Taiwan where the species was collected.

Diagnosis: Colletotrichum tainanense differs from its closest phylogenetic neighbour C. salsolae in the culture
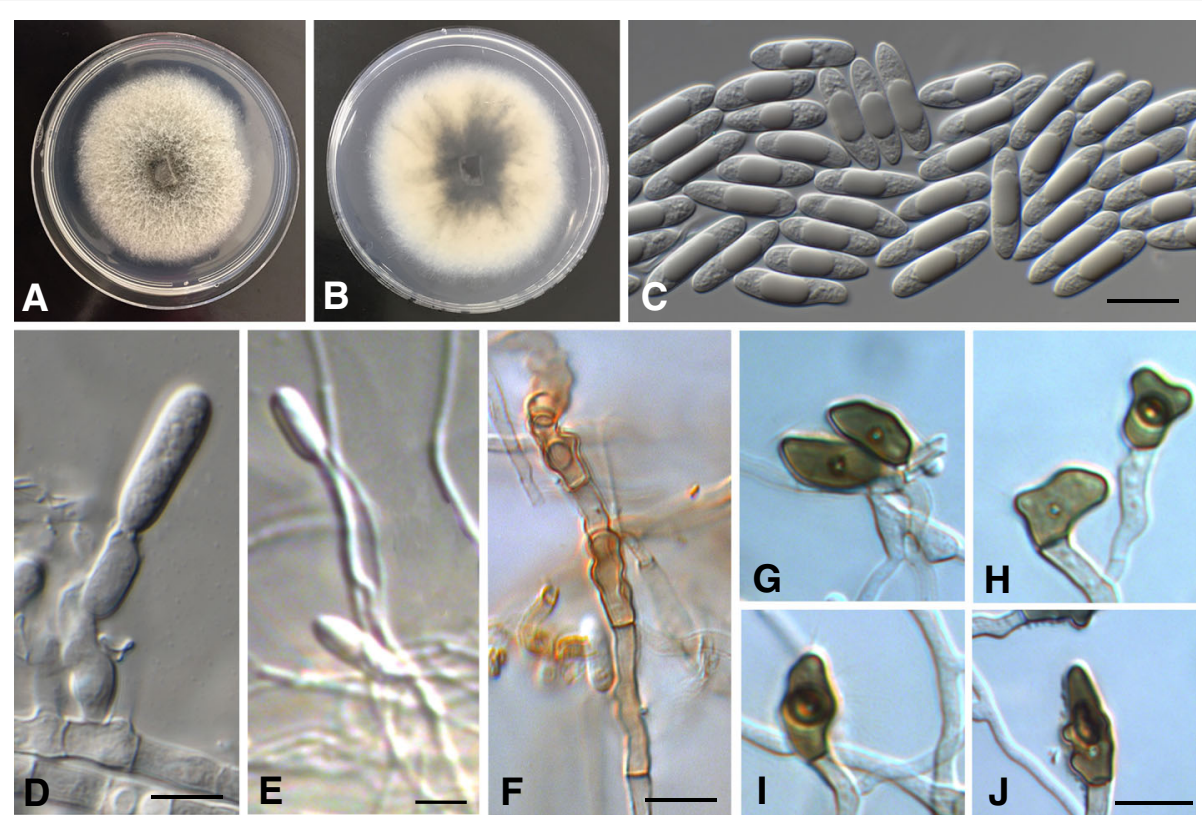

Fig. 8 Colletotrichum tainanense (CBS 143666). a Colony on PDA. b Reverse side of the colony on PDA. c Conidia. d-e Conidiophores and Conidia. f Melanised hypae $\mathbf{g}$-j Appressoria. Bars $=10 \mu \mathrm{m}$ 
characteristics on PDA, sparse aerial mycelium and pale mouse-grey surface mycelium, whereas $C$. salsolae produces a layer of acervuli-like structures with deep orange brown conidial masses and numerous setae. The two species are separable using all the genes tested except for ITS and most effectively with gapdh (7 bp difference), tub2 (6 bp difference) and act (5 bp difference) sequences. There is only one bp difference in the chs-1 sequence between the two species.

Type: Taiwan: Tainan: on fruit of Capsicum annuum, Aug. 2014, Z.M. Sheu (CBS H-143666 - holotype; CBS 143666 = CPC 30245 = UOM $1120=$ Coll $1298-$ ex-type cultures).

Description: Sexual morph not observed. Asexual morph on PDA. Vegetative mycelium branched, hyaline, smooth-walled, septate, hyphae $2-3 \mu \mathrm{m}$ diam, melanised with time. A single conidioma found on a PDA plate, sterile on SNA, MEA, and OA. Chlamydospores and setae not observed. Conidiophores subcylindrical, flexuous, 1-2-septate, hyaline, smooth to pale brown, branched. Conidiogenous cells subcylindrical, hyaline, smooth, phialidic with periclinal thickening. Conidia hyaline, smooth, aseptate, subcylindrical to subclavate, straight or slightly curved, apex obtuse, tapering at base to protruding truncate hilum, $1.5-2 \mu \mathrm{m}$ diam, prominently guttulate, $(16-) 17-18(-22) \times(4.5-) 5 \mu \mathrm{m}$. Appressoria single or in loose groups, often narrow-cylindric, medium to dark brown, often tapering towards apex, the edge entire or undulate sometimes irregularly lobed $(6.5-) 10.5(-14.5) \times(6-) 5(-9.5) \mu \mathrm{m}$.

Culture characteristics: Colonies on PDA $45 \mathrm{~mm}$ diam after $7 \mathrm{~d}(6.5 \mathrm{~mm} / \mathrm{d})$, colonies flat, with moderate aerial mycelium. On OA surface pale mouse-grey. On PDA surface pale mouse-grey, reverse mouse-grey. On MEA surface pale mouse-grey, reverse olivaceous grey.

Notes: The closest match in a blastn search with the gapdh sequence with $99 \%$ identity (2 bp difference) was GenBank KC790761 Colletotrichum sp. strain MTCC 9664 while the closest match with the act sequence with 99\% identity (2 bp difference) was GenBank KY995522 C. siamense strain LJDY1-2. The closest match with the tub2 sequence with $99 \%$ identity (7 bp difference) was GenBank MF143931 C. siamense strain 31-B-1.

Colletotrichum endophyticum Manamgoda et al., Fung. Diversity 61: 112 (2013); as 'endophytica'.

Description: Colonies on PDA $42 \mathrm{~mm}$ diam after $7 \mathrm{~d}$ $(5.5 \mathrm{~mm} / \mathrm{d})$, pale orange to white aerial mycelium; reverse pale white to orange and black at the centre and numerous orange conidiomata scattered over the surface. Chlamydospores not observed. Conidiomata present, conidiophores formed directly on hyphae. Setae present, moderately brown, 47-95 $\times 3-6 \mu \mathrm{m}, 3-$ 4-septate, tapering acute apices. Conidiophores hyaline, smooth-walled and unbranched. Conidiogenous cells hyaline, smooth-walled, aseptate, subcylindrical, $12-21 \times 3-4 \mu \mathrm{m}$. Conidia hyaline, smooth-walled, aseptate, straight, cylindrical with two ends obtuse, $(10.5-) 12.5-13(-14.5) \times(3-) 4.5-5(-6.5) \mu \mathrm{m}$. Appressoria single or in loose groups, brown, slightly lobed, $(10.5-) 12(-15) \times(3-) 4.5(-10) \mu \mathrm{m}$.

Notes: Colletotrichum endophyticum was first described as a grass endophyte of Pennisetum purpureum from northern Thailand (Manamgoda et al. 2013). Later, it was reported from several other host species including Capsicum in China (Diao et al. 2017). The length of conidia of the isolate from Thailand (UOM 1137) was slightly shorter than that of the ex-type (LC0324) of C. endophyticum (conidia 13-19(-21) × (3.5-)4.5-5.5 $\mu \mathrm{m}$ ).

Material examined: Thailand: Kanchanaburi: from fruit lesion of Capsicum annuum, 2010, P.W.J. Taylor \& O. Mongkolporn (culture UOM 1137 = F5-2D).

\section{Colletotrichum fructicola Prihast. et al., Fung. Diversity 39: 158 (2009).}

Description: Colonies on PDA $65 \mathrm{~mm}$ diam after $7 \mathrm{~d}$ $(8.5-11 \mathrm{~mm} / \mathrm{d})$, flat with entire edge, aerial mycelium dense, cottony, pale grey to white aerial mycelium and numerous black stroma scattered over the surface, grey in the centre, white at the margin; reverse greyish green. Chlamydospores not observed. Conidiomata acervular, Setae was observed, brown, smooth-walled, 1-2-septate, $60 \mu \mathrm{m}$ long, tapering acute apices. Conidiophores hyaline, septate, branched. Conidiogenous cells hyaline, cylindrical or ampulliform, 7-17.5 $\mu \mathrm{m}$. Conidia hyaline, aseptate, smooth-walled, cylindrical, both ends obtuse, (10.5-)12.5-13(-18.5) × (3-) 4-5.5(-6.5). Appressoria not observed.

Notes: The sexual morph of these isolates was not observed in culture. Conidial length of isolate CPC 28644 was slightly longer than that of the ex-type (ICMP $18581=$ BPD-I16) of C. fructicola (conidia 9.7$14 \times 3-4.3 \mu \mathrm{m}, x=11.53 \pm 1.03 \times 3.55 \pm 0.32 \mu \mathrm{m}$; Prihastuti et al. 2009).

Material examined: Thailand: Chiang Mai: from fruit lesion of Capsicum annuum, 7 Jun. 2015, P.W.J. Taylor E O. Mongkolporn (cultures CPC 28644 and CPC 28645). 
Taiwan: Cyonglin, Hsinchu, from fruit lesion of mature red fruit of Capsicum sp. (sweet pepper), 22 Apr. 2015, Z.M. Sheu (culture UOM 1139=coll 1318); Nantou, Renai, from fruit lesion of green fruit of Capsicum sp. (sweet pepper), 4 Sep. 2008, Z.M. Sheu E C. Wang (culture UOM 1138 = coll-853).

\section{Colletotrichum karsti You L. Yang et al. Cryptogamie, Mycologie 32: 241 (2011); as 'karstii'.}

Description: Colonies on PDA $65 \mathrm{~mm}$ diam after $7 \mathrm{~d}$ (6.5$10.5 \mathrm{~mm} / \mathrm{d}$ ), flat with entire edge, orange to white aerial mycelium and numerous orange conidial masses scattered over the surface, white at the margin; reverse yellow to orange. Chlamydospores not observed. Conidiomata acervular, setae were observed, brown, smooth-walled, 24-septate, $60 \mu \mathrm{m}$ long, base submerged, tapered towards apex, tip mostly acute. Conidiophores hyaline, septate, branched, (10.5-)12-38(-47.5) × (3-)4-5.5(-6.5) $\mu \mathrm{m}$. Conidiogenous cells hyaline, cylindrical or ampulliform, 7$15.5 \mu \mathrm{m}$. Conidia hyaline, aseptate, smooth-walled, short, cylindrical, both ends obtuse or one end slightly acute or truncate at the base, (11.5-)12.5-13(- 15.5) × (3-)4-5(6.5) $\mu \mathrm{m}$. Appressoria single or in loose groups, brown, subglobose, circular outline, $6-12.5 \times 3.5-8 \mu \mathrm{m}$.

Notes: The four isolates identified from Indonesia in the boninense complex produced distinct short conidia compared to the ex-epitype culture of C. karsti (14.5$17 \times 5-6.5 \mu \mathrm{m}$; Yang et al. 2011). However, high variability of conidia size between different strains of C. karsti were reported by Damm et al. (2012a, 2012b) where the conidia measurements of CBS 129833 were (11.5-)12.5$14(-14.5) \times(5-) 5.5-6(-6.5) \quad \mu \mathrm{m}, \quad$ mean $\pm \mathrm{SD}=13.1 \pm$ $0.7 \times 5.8 \pm 0.4 \mu \mathrm{m} ;$ and CBS 111998 had a conidium length up to $18.5 \mu \mathrm{m}, \mathrm{L} / \mathrm{W}$ ratio $=2.8$. These isolates did not form a sexual morph in culture. Although these four isolates formed a fully supported (100\% BS/1 PP) subclade within C. karsti, all the individual gene trees (data not shown) did not provide significant support to justify introducing a cryptic species for these isolates.

Material examined: Indonesia: Jeneponto, from fruit lesions of Capsicum annuum, 7 Jun. 2015, P.W.J. Taylor $\mathcal{E}$ A. Nasruddin (cultures CPC 28553, CPC 28554); from fruit lesion of mature red fruit and peduncle lesions of Capsicum sp. Jun. 2015, P.W.J. Taylor \& A. Nasruddin (cultures CPC 28601, CPC 28602).

\section{Colletotrichum plurivorum Damm et al., Stud. Mycol. 92: 31 (2019).}

Description: Colonies on PDA $63 \mathrm{~mm}$ diam after $7 \mathrm{~d}$ $(8 \mathrm{~mm} / \mathrm{d})$, grey to dark brown aerial mycelium; reverse grey to light brown with yellow-orange in the centre with abundant acervular conidiomata that ooze pale orange conidial masses at the centre, Chlamydospores not observed. Conidiomata present (near the inoculation point), conidiophores formed directly on hyphae. Sclerotia present. Setae present, medium brown, 94-125 × 4-6 $\mu \mathrm{m}, 1-4$-septate, tapering towards acute apices, often with a constriction at the apex. Conidiophores hyaline to pale brown, smooth-walled, septate and branched. Conidiogenous cells hyaline, smooth-walled, aseptate, subcylindrical, straight to gently curved, $26-48 \times$ 3-4 $\mu \mathrm{m}$, phialidic, periclinal thickening conspicuous. Conidia hyaline, smooth-walled, aseptate, straight, cylindrical with two ends obtuse or one end slightly acute, $(13.5-) 14-16(-18.5) \times(4-) 5(-6.5) \mu \mathrm{m}$. Appressoria single or in loose groups, medium brown, irregular in shape, crenate or lobed outline, (10.5-)12(-23) $\times(3.5-) 5.5(-$ 11.5) $\mu \mathrm{m}$. Sexual morph on PDA. Ascomata perithecia, formed after 2 wk., solitary, semi-immersed or immersed in the agar medium, nonstromatic, subspherical to ovoid, ostiolate, glabrous, medium brown, 96-130 $\times$ $160-200 \mu \mathrm{m}$. Peridium 10-12.5 $\mu \mathrm{m}$ thick, composed of pale to medium brown flattened angular cells 3.5$10 \mu \mathrm{m}$ diam. Ascogenous hyphae hyaline, smooth-walled, delicate, rarely visible. Interascal tissue not observed. Asci unitunicate, 8-spored, cylindrical, tapering to apex and base, smooth-walled, $51-65 \times 9.5-13 \mu \mathrm{m}$, the base truncate. Ascospores biseriately arranged, aseptate, hyaline, smooth-walled, fusiform, slightly curved, base rounded, apex acute or rounded, (13.5-)15-18(-22) $\times$ 5-6(-6.5) $\mu \mathrm{m}$,

Notes: The conidial length of the isolates examined (CPC 28638, CPC 28639) was variable and fell within the range of the ex-type isolate (CBS 125474) of C. plurivorum $(15-17 \times 5.5 \mu \mathrm{m}$; Damm et al. 2019).

Material examined: Thailand: Chiang Rai, from leaf lesions of Capsicum annuum, 7 Jun. 2015, P.W.J. Taylor (cultures CPC 28638 and CPC 28639); Bangkok, restaurant in Phaya Thai area, infected tissue of Capsicum sp. Jun. 2015, P.W.J. Taylor (culture UOM 1004).

\section{Colletotrichum scovillei Damm et al., Stud. Mycol. 73: 100 (2012).}

Decription: Colonies on PDA $20-38 \mathrm{~mm}$ diam after $7 \mathrm{~d}$ $(5-6.2 \mathrm{~mm} / \mathrm{d})$, flat with entire margin; surface covered with short light pink to orange aerial mycelium, turn grey with time, margin whitish to pale pink, reverse rosy buff, olivaceous grey to brown-grey in the centre; reverse orange to salmon, dark at the centre. Chlamydospores not observed. Conidiomata acervular, setae not observed, Conidiophores hyaline, septate, branched. 
Conidiogenous cells hyaline, cylindrical or ampulliform, 7-17.5 $\mu \mathrm{m}$, apex 1-3 $\mu \mathrm{m}$ diam. Conidia hyaline, aseptate, smooth-walled, mostely fusiform, one end rounded, one end acute, (5.5-)9.5-10(-12) $\times(2.5-) 3(-4)$. Conidia in mass with salmon to orange colour. Appressoria single or in loose groups, medium brown, ovoid, entire to crenate margin, (4-)5.5(-12.5) × (3.5-)4.5-5(-6.5) $\mu \mathrm{m}$.

Notes: The majority of isolates identified as C. scovillei had similar spore shape and spore sizes, compared to the type specimen (10.5-)12.5-15(-16.5) $\times(3-) 3.5-$ $4(-4.5) \mu \mathrm{m}$, described by Damm et al. (2012a, 2012b). However, some isolates had varying colony colour, different colony growth rates and small differences in spore measurements.

Material examined: Indonesia: Gowa, from fruit lesions of Capsicum annuum, 7 Jun. 2015, P.W.J. Taylor $\mathcal{E}$ A. Nasruddin (cultures CPC 28577 and CPC 28579); West Java: from fruit lesion of Capsicum annuum, Dec. 2014, F. Fitriyah, UOM 1146/ EWINDO 10. Thailand: Chiang Mai: from fruit lesions of Capsicum sp. 2008, O. Mongkolporn (cultures UOM 1101/313, UOM 1111).

\section{Colletotrichum siamense Prihast. et al., Fung. Diversity 39: 98 (2009)}

Description: Colonies on PDA $79 \mathrm{~mm}$ diam in $7 \mathrm{~d}$ (5.5-6 $\mathrm{mm} / \mathrm{d})$. Pale yellow-white, grey, dense cottony aerial mycelium with orange acervular conidiomata at the centre; reverse pale yellowish. Chlamydospores not observed. Conidiomata acervular, conidiophores formed on a cushion of roundish and medium brown cells. Setae not observed. Conidiophores hyaline, branched. Conidiogenous cells hyaline, cylindrical to ampulliform, 6.5-16 $\mu \mathrm{m}$. Conidia hyaline, aseptate, smooth-walled, fusiform to cylindrical, both ends bluntly rounded, (13-)14(-15.5) × (3-)4(-5.5) $\mu \mathrm{m}$. Appressoria dark brown, solitary, circular, entire to crenate margin, $(4.5-) 7.5(-10) \times(3.5-) 3(-5.5) \mu \mathrm{m}$.

Notes: Colletotrichum siamense isolates from different countries showed variation of morphological characters, in growth rates and culture morphology on PDA. Representative conidial measurements for isolates representing different subclades in the phylogenetic trees (Figs. 2, 3) are: CPC 30233 (Gowa, Indonesia), 12.5-17 × 2.5$5.5 \mu \mathrm{m}$; UOM 1132 (Ratchaburi, Thailand) 9.5-14.5 $\times$ 3.5-5 $\mu \mathrm{m}$; UOM 1126/ F4-1C (Kanchana Buri, Thailand) 12-15 × 5-7 $\mu \mathrm{m}$; UOM 1116 (Kandy, Sri Lanka) 10.5$16.5 \times 3.5-5.5$. These morphological characters within a subclade were highly consistent within each country. The species was described by Prihastuti et al. (2009); conidia of the ex-holotype specimen (ICMP 18578/
BDP-I2) were reported as $7-18.3 \times 3-4.3 \mu \mathrm{m}(x=10.18 \pm$ $1.74 \times 3.46 \pm 0.36$ ), which encompasses the range observed in our isolates. This species was reported to be biologically and geographically diverse, and is found on many hosts across several tropical and subtropical regions (Weir et al. 2012).

Material examined: Indonesia: Gowa, from fruit lesion of Capsicum annuum, 7 Jun. 2015, P.W.J. Taylor $\mathcal{E}$ A. Nasruddin (culture CPC 30233); Jeneponto, from fruit lesion of Capsicum sp. 7 Jun. 2015, P.W.J. Taylor $\mathcal{E}$ A. Nasruddin (culture CPC 30209). Thailand: Ratchaburi, from fruit lesion of Capsicum sp., Jan. 2010, P.W.J. Taylor E O. Mongkolporn (culture UOM 1132); Kanchanaburi, from fruit lesion of Capsicum sp. Jan. 2010, P.W.J. Taylor \& O. Mongkolporn (culture UOM 1126 = F4-1C). Sri Lanka: Kandy, from fruit lesion of Capsicum sp. Sep. 2013, D.D. De Silva \& N. Ranathunge (culture UOM 1116).

\section{Colletotrichum tropicale E.I. Rojas et al., Mycologia 102: 1331 (2010)}

Description: Colonies on PDA $45 \mathrm{~mm}$ diam in $7 \mathrm{~d}(6.5$ $\mathrm{mm} / \mathrm{d}$ ). Colonies flat, spreading, with moderate aerial mycelium, On OA surface smoke grey. On PDA surface olivaceous grey to smoke grey, reverse olivaceous grey, numerous orange conidiomata scattered over the surface. On MEA surface dirty white, reverse ochreous. Asexual morph on OA. Vegetative mycelium consisting of hyaline to pale brown, smooth-walled, septate, branched, 2-2.5 $\mu \mathrm{m}$ diam hyphae. Chlamydospores not observed. Setae rare (only two seen), straight, medium brown, finely verruculose, 2-3-septate, to $120 \mu \mathrm{m}$ long, apex subobtusely rounded. Conidiomata acervular, 150-250 $\mu \mathrm{m}$ diam, with orange conidial mass. Conidiophores subcylindrical, flexuous, 1-3-septate, hyaline, smooth, branched, $15-25 \times 3.5-4.5 \mu \mathrm{m}$. Conidiogenous cells subcylindrical, hyaline, smooth, phialidic with periclinal thickening, 7-15 × 3.5-4.5 $\mu \mathrm{m}$. Conidia hyaline, smooth, aseptate, subcylindrical, straight, apex obtuse, tapering at base to protruding truncate hilum, $1.5-2 \mu \mathrm{m}$ diam, prominently guttulate, $(13-) 14-16(-17) \times(3.5-) 4-$ $5(-6) \mu \mathrm{m}$. Appressoria not observed. Sexual morph not observed.

Material examined: Indonesia, Makassar, from fruit lesion of Capsicum annuum, 7 Jun. 2015, P.W.J. Taylor $\mathcal{E}$ A. Nasruddin (culture CPC 28607).

\section{Prevalence of sampled Colletotrichum species}

Overall, C. truncatum was the most prevalent species (44\%) isolated from infected chili fruit (Fig. 9) and was readily identified by its falcate spores and abundant setae 

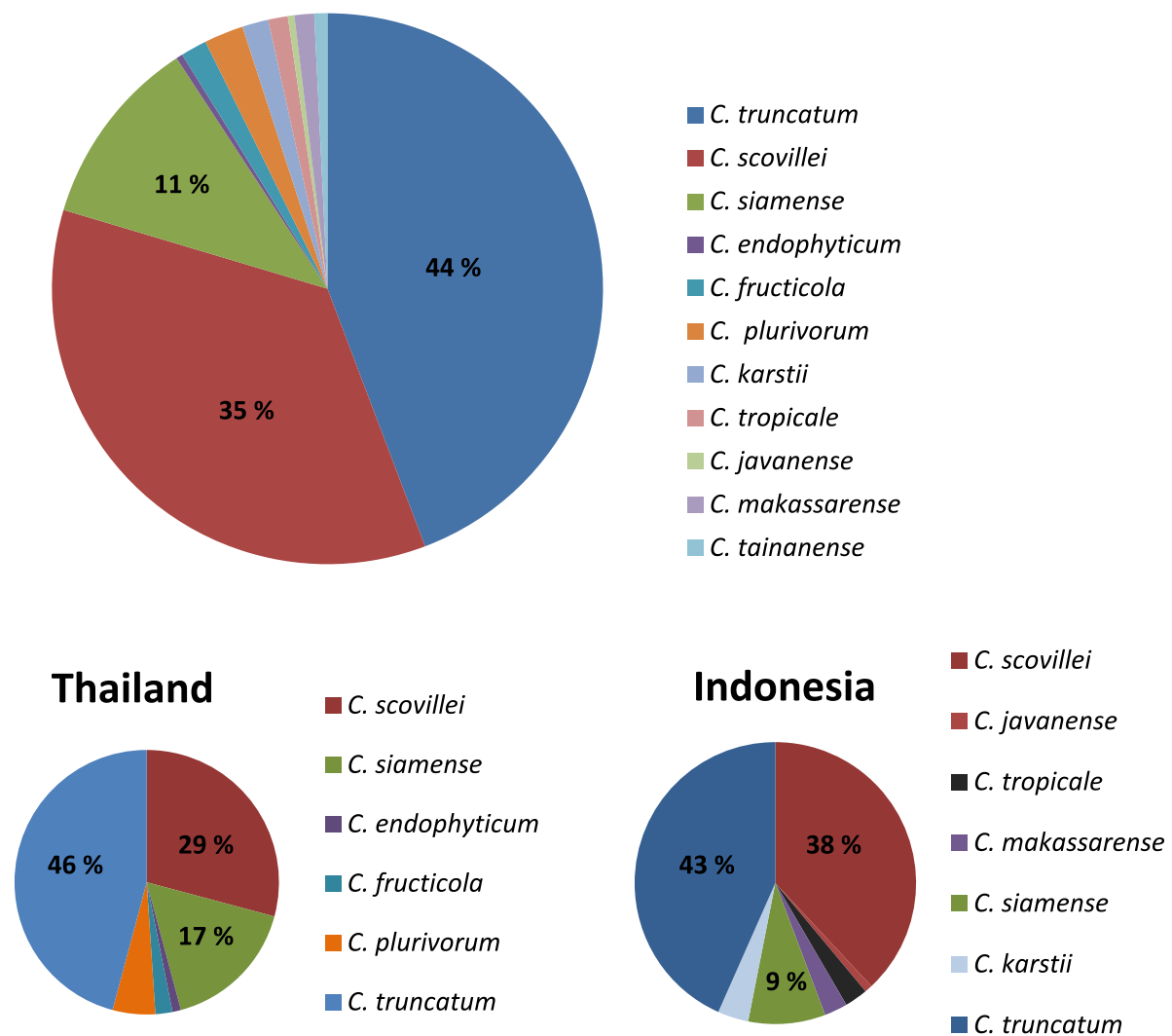

Fig. 9 Prevalence of Colletotrichum species as a percentage of the total isolates collected in all regions and in Indonesia and Thailand specifically

in the necrotic lesions. Of the species with straight conidia, C. scovillei (acutatum complex), was the most common species throughout the surveyed countries (35\%), except for Sri Lanka where this species was not isolated. Colletotrichum siamense (gloeosporioides complex) was the next most common species that occurred in
Thailand, Sri Lanka and Indonesia (11\%). The remaining species were represented by fewer than $10 \%$ of the total number of isolates.

In Indonesia, C. scovillei was isolated from infected chili fruit in all surveyed regencies of South Sulawesi, except in Makassar, and in the field trial site in West

Table 5 Mean lesion size of symptoms caused by Colletotrichum species with straight conidia on inoculated mature red fruit of Capsicum annuum cv. Bangchang

\begin{tabular}{|c|c|c|c|c|c|c|c|}
\hline \multicolumn{4}{|c|}{ Wound inoculation } & \multicolumn{4}{|c|}{ Non-wound inoculation } \\
\hline Species & Least squares mean $\mathrm{mm}$ & Standard Error & t-grouping ${ }^{a}$ & Species & Least squares mean $\mathrm{mm}$ & Standard Error & t-grouping ${ }^{a}$ \\
\hline C. scovillei & 20.3 & 0.09 & a & C. javanense & 9.4 & 0.28 & $a b$ \\
\hline C. javanense & 15.6 & 0.35 & $a b$ & C. scovillei & 9.1 & 0.07 & a \\
\hline C. siamense & 9.7 & 0.11 & bc & C. fructicola & 3.6 & 0.2 & bc \\
\hline C. karsti & 9.4 & 0.2 & bcd & C. endophyticum & 2.8 & 0.29 & $b c$ \\
\hline C. fructicola & 7.8 & 0.25 & be & C. karsti & 2 & 0.16 & c \\
\hline C. tainanense & 6.9 & 0.25 & be & C. tainanense & 1.5 & 0.2 & c \\
\hline C. makassarense & 6.4 & 0.18 & ce & C. siamense & 1.3 & 0.09 & c \\
\hline C. plurivorum & 5.3 & 0.16 & de & C. makassarense & $<1.0$ & 0.14 & c \\
\hline C. endophyticum & 4.4 & 0.35 & ce & C. tropicale & $<1.0$ & 0.16 & c \\
\hline C. tropicale & 4.1 & 0.2 & de & C. plurivorum & $<1.0$ & 0.13 & c \\
\hline control & 0 & 0.35 & e & control & 0 & 0.29 & c \\
\hline
\end{tabular}

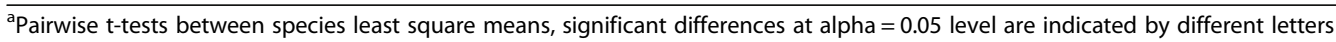


Java. Colletotrichum siamense was also isolated from throughout the region, from Gowa, Jeneponto and Makassar. The two new species, C. makassarense and C. javanense were isolated from Makassar and West Java, respectively.

In Thailand, C. scovillei was isolated mostly from the northern provinces of Chiang Mai and Chiang Rai, but was also obtained from infected chili fruit in a trial site of Kasetsart University in Nakhon Pathom. The Western provinces had a high incidence of $C$. siamense and one isolate of $C$. endophyticum was collected from Kanchana Buri. Colletotrichum plurivorum was isolated from chili leaves with necrotic lesions in Chiang Rai and from necrotic lesions of chili fruit found in a restaurant in Phaya Thai area of Bangkok. In addition, C. fructicola was identified from fruit collected from Chiang Mai.

In Taiwan, an isolate was identified as a new species, C. tainanense, collected from infected chili fruit in the Tainan province, and C. fructicola was identified from fruit in Hsinchu and Nantou, Taiwan. Colletotrichum plurivorum was also identified from a fruit collected in Johor, Malaysia.

\section{Pathogenicity}

All the Colletotrichum species caused anthracnose symptoms on wounded fruit, but there were significant differences in severity of the symptoms. On wounded fruit, isolates of C. scovillei and C. javanense showed the highest disease severity, producing large, necrotic lesions with mean lesion sizes $15.6-20.3 \mathrm{~mm}$ (Table 5). On non-wounded fruits, all species were less pathogenic, with mean lesion sizes less than 10 $\mathrm{mm}$. Colletotrichum makassarense, C. tropicale and C. plurivorum, produced only very small lesions or no visible symptoms (mean lesion size $<1 \mathrm{~mm}$ ) $10 \mathrm{~d}$ after inoculation of non-wounded fruits. Colletotrichum javanense and $C$. scovillei isolates were the most pathogenic in non-wounded fruit and produced lesions with mean sizes of 9.4 and $9.1 \mathrm{~mm}$ respectively. Lesions caused by $C$. scovillei were significantly larger than those caused by all other species except for $C$. javanense in wounded fruit and $C$. endophyticum in unwounded fruit. Significance of the pairwise t-tests is strongly dependent on the number of isolates of each species sampled, so the groupings shown in Table 5 do not simply change with the magnitude of the difference of the means; a large difference may not be significant if there are small sample sizes for both species while a smaller difference may be significant. In particular, comparisons involving C. javanense and $C$. endophyticum are very imprecise as only one isolate of each species was tested.

\section{DISCUSSION}

Colletotrichum isolates collected from infected fruit and leaf tissue of chili plants from Thailand, Indonesia, Taiwan, Sri Lanka, and Malaysia were allocated to different species complexes with 11 Colletotrichum species being identified and three new species described.

Colletotrichum truncatum was the most prevalent species of Colletotrichum causing anthracnose of chili in Asia, which supports previous reports of C. truncatum being widely distributed on chili fruit throughout Asia, Australia, and South America (Sharma et al. 2014; De Silva et al. 2017a; Diao et al. 2017; Mongkolporn and Taylor 2018). Colletotrichum truncatum has a broad host range infecting many crop species (https://nt.arsgrin.gov/fungaldatabases/; Ranathunge and Hewa Bajjamage 2016).

The remaining $56 \%$ of isolates with straight conidia belonged to the gloeosporioides, acutatum, boninense and orchidearum species complexes. Of these, C. scovil$l e i$, in the acutatum complex, was the most prominent species (35\% of the total isolates) and was distributed in Indonesia, Malaysia, Thailand and Taiwan. However, $C$. scovillei was not identified in the survey of Sri Lanka, possibly because of the small number of samples assessed. Previous studies have also reported the predominance of C. scovillei in Asia and Brazil (Diao et al. 2017, Mongkolporn and Taylor 2018), but this species has not been identified in Australia (De Silva et al. 2017a) and hence remains an important biosecurity threat to the Australian capsicum/chili industry. Further surveys are required to confirm the presence of C. scovillei in Australia and Sri Lanka.

Colletotrichum siamense, in the gloeosporioides complex, was also prominent ( $11 \%$ of total isolates) in causing anthracnose of chili fruit in Indonesia, Sri Lanka and Thailand, but was not detected in Malaysia and Taiwan. Nevertheless, Noor and Zakaria (2018) reported the identification of C. siamense in Malaysia possibly due to a larger sampling size of infected chili across states in Malaysia. Within the C. siamense clade, small subclades were observed that coincided with different geographical regions from where the isolates were collected. Colletotrichum siamense has been reported to infect chili in Asia, Australia, Brazil, and is a common pathogen of many other plant species (Weir et al. 2012; James et al. 2014; Sharma and Shenoy 2014; Liu et al. 2016a, 2016b; de Oliveira et al. 2017; De Silva et al. 2017a; Diao et al. 2017; Suwannarat et al. 2017).

Colletotrichum siamense isolates from different countries appeared to show different morphological characters with varying growth rates and culture morphologies. This variability in morphological characters indicated that this taxon has high intra-specific diversity. The combined gene analyses of ApMat and gs sequences also 
supported the distinction of subclades within the C. siamense clade. In the last few years, there has been significant debate on whether $C$. siamense s. lat. should be separated into different species groups within the gloeosporioides complex, with the number of accepted species ranging from one to seven (Weir et al. 2012; Udayanga et al. 2013). However, a recent case study concluded that C. siamense s. lat. was a single species rather than a species complex as no independent evolutionary lineages were found within this species (Liu et al. 2016a).

Colletotrichum tropicale is reported for the first time as causing anthracnose in Capsicum in Indonesia. Rojas et al. (2010) noted that $C$. tropicale was initially isolated from a wide range of hosts in forests in tropical America, from rotting fruit and as a leaf endophyte. Silva et al. (2017) recently reported C. tropicale causing chili anthracnose in Brazil. Colletotrichum tropicale was also reported from Japan, Panama, Thailand, and from other host species (Mongkolporn and Taylor 2018).

Colletotrichum fructicola is reported for the first time causing chili anthracnose in Thailand and Taiwan. Colletotrichum fructicola was previously reported to cause anthracnose in chili from India and China (Sharma and Shenoy 2014; Diao et al. 2017). Prihastuti et al. (2009) originally isolated C. fructicola from coffee berries in Thailand, and then C. fructicola was reported as a leaf endophyte from several plants in South America (Weir et al. 2012; Vieira et al. 2014) Colletotrichum fructicola has a wide host range and was reported by Weir et al. (2012) as a biologically and geographically diverse species.

All the species in the gloeosporioides complex were identified using combined multi-locus gene analyses, based on the ITS, gapdh, chs-1, act and tub2 genes, which showed higher diversity on chili than those in the acutatum, boninense and orchidearum species complexes. Phylogenetic tree provided good resolution of the species with high support values, which supported the species boundaries and identified the novel species.

Phylogenetic trees built from ApMat and gs gene sequences had similar topologies to the multigene phylogenetic tree confirming that the ApMat and gs loci were highly informative and that they distinguished most species in the gloeosporioides species complex (Silva et al. 2012; Sharma et al. 2013; Liu et al. 2015). However, some recent new species (Diao et al. 2017; Marin-Felix et al. 2017) were unable to be placed in the ApMat and gs phylogenetic tree due to the absence of the ApMat gene sequence data. Although there were reports that the $g s$ gene alone is not a good marker for differentiating C. siamense isolates (Weir et al. 2012), these data showed multiple base pair differences in gene sequences of the gs loci of $C$. siamense species similar to the ApMat locus. In addition, the lack of noticeable subclading in $C$. siamense in the 5-gene tree compared to the ApMat and gs tree, confirmed that the ApMat and gs loci were more informative than the other five gene loci. The ApMat gene has been shown previously to improve the systematics of the gloeosporioides species complex, providing complementary phylogenetic information compared to other loci (Silva et al. 2012). Liu et al. (2015) also applied the ApMAT gene in a more recent molecular phylogenetic analyses of the species in this complex and discussed the merit of using ApMat and ApMat in combination with $g s$ to resolve the phylogeny.

Although four isolates from Indonesia were identified as C. karsti in the boninense complex, they formed a subclade within the $C$. karsti species clade and had different conidial sizes to the ex-type strain of C. karsti (Yang et al. 2011), suggesting that these might be a new species. However, sufficient phylogenetic support was not observed in all the individual gene trees to justify the introduction of a novel species. Besides, Damm et al. (2012a, 2012b) reported that the conidium size of $C$. karsti was quite variable. Colletotrichum karsti has been reported from China and India to cause anthracnose disease in Capsicum spp. (Liu et al. 2016b; Saini et al. 2016; Diao et al. 2017). Colletotrichum karsti has the widest known host range and distribution of all species in the boninense complex (Damm et al. 2012b). Most of the $C$. karsti strains had been isolated as endophytes but a few were derived from diseased plant tissues. This species has mostly been isolated from dicotyledonous plants, but some have occurred on monocotyledonous families, especially Orchidaceae and Musaceae (Damm et al. 2012b).

Colletotrichum plurivorum was identified for the first time causing anthracnose in Thailand and Malaysia. The five C. plurivorum isolates from chili in Thailand formed a distinct subclade with high support values within the C. plurivorum subclade, and separated from C. cliviicola (syn. C. cliviae, Damm et al. 2019). In addition, the $C$. plurivorum isolates formed a characteristic sexual morph in culture, which was not reported for C. cliviicola (Yang et al. 2009).

Recently, Damm et al. (2019) resolved the taxonomic placement of several Colletotrichum strains which did not belong to any of the accepted species complexes and assigned them to three new species complexes including the orchidearum complex. Recent studies in China and Brazil also identified multiple species belonging to these complexes, including C. brevisporum, C. cliviicola, C. liaoningense, and C. plurivorum that caused anthracnose disease in chili (Liu et al. 2016b; De Silva et al. 2017b; Diao et al. 2017). Colletotrichum plurivorum belongs to the orchidearum complex with many isolates reported to have a large host range (Damm et al. 2019). The type specimen was described as new from Coffea in Vietnam 
(Nguyen et al. 2010). Colletotrichum plurivorum was originally described as C. sichuanensis from Capsicum annuum in the Sichuan Province of China (Liu et al. 2016b). However, the name was invalid, because no holotype specimen was cited (Mongkolporn and Taylor 2018; Damm et al. 2019).

Pathogenicity tests of Colletotrichum spp. from chili showed that while all the species were pathogenic on chili fruits after wounding the fruit surface, most produced a low level of infection on non-wounded fruit. This illustrates the importance of the cuticle acting as a barrier to infection by Colletotrichum spp. (Auyong et al. 2015) and emphasises the need for informed and standardised inoculation techniques in pathogenicity assays. Some species such as C. tropicale, C. makassarense and C. plurivorum which produced a low level of infection in the assays on non-wounded fruit, may have a predominantly endophytic lifestyle then switch to a necrotrophic life style to complete their life-cycle (De Silva et al. 2017b). However, further pathogenicity tests on different chili cultivars and at different fruit maturity stages are necessary to comprehensively evaluate their pathogenicity. Pathogenicity testing of C. plurivorum on chili leaves and fruits showed that the isolates collected from Chiang Rai and Malaysia could infect leaves but not fruit (results not shown) and suggested they might be specialised leaf pathogens. In contrast, two isolates of C. plurivorum from Bangkok did not infect leaves but did infect wounded fruits. These results demonstrate the pathogenic variation that can exist within a single species.

Mongkolporn et al. (2010) identified pathotypes of $C$. truncatum, C. scovillei (as C. acutatum) and C. siamense (as C. gloeosporioides) within isolates of each species from Thailand. Pathotypes were identified by inoculating wounded fruit of Capsicum baccatum and C. chinense genotypes. All the isolates identified as C. gloeosporioides and C. acutatum in Mongkolporn et al. (2010) were subsequently re-identified as C. siamense and C. scovillei, respectively except for isolate UOM 1137 (F5-2D), which was identified as $C$. endophyticum. The isolate UOM 1137 was pathogenic in both the wound and non-wound bioassays, and was classified in the most virulent $C$. siamense pathotype group (PCg1-R) in Mongkolporn et al. (2010). This contrasts with the study by Manamgoda et al. (2013) where C. endophyticum was described as an endophyte of Pennisetum purpureum. The severity of infection in chili may indicate that Capsicum annuum was the preferred host for $C$. endophyticum and $P$. purpureum was a less favoured host, where the pathogen infected but existed in an endophytic lifestyle. In addition, isolate UOM 1137 also has shorter spores than the type isolate of $C$. endophyticum, thus further isolates of this species need to be collected from chili plants and $P$. purpureum in Thailand to confirm taxonomy and pathogenicity.

\section{CONCLUSIONS}

Multigene phylogenetic analyses of Colletotrichum species causing anthracnose disease of Capsicum in Asia showed high species diversity with the identification of 11 different Colletotrichum species, including three novel species. Although $C$. siamense has been reported as infecting many plant species before, this was the first report of $C$. siamense causing anthracnose in chili in Indonesia and Sri Lanka. This was also the first report of C. fructicola infecting chili in Thailand and Taiwan. In addition, all three novel species were new additions to the Colletotrichum species causing anthracnose in chili. More surveys in countries in Asia and Oceania need to be conducted to identify the diversity and prevalence of species causing chili anthracnose. Understanding of the taxonomy and the pathogenicity of Colletotrichum spp. has great significance to fruit and vegetable industries, where there are serious biosecurity implications of incursion by exotic pathogens.

\section{Abbreviations}

AGRF: Australian Genome Research Facility; BI: Bayesian inference analyses; CBS: Westerdijk Fungal Biodiversity Institute, The Netherlands; Cl: Consistency index; DIC: Differential interference contrast; DNA: Deoxyribonucleic acid; MCMC: Markov chain Monte Carlo algorithm; MEA: Malt extract agar; ML: Maximum likelihood; MP: Maximum parsimony; OA: Oatmeal agar; PAUP: Phylogenetic analysis using parsimony; PCR: Polymerase chain reaction; PDA: Potato dextrose agar; PP: Posterior probabilities; RC: Rescaled consistency index; RI: Retention index; SNA: Synthetic nutrient-poor agar; TBR : Tree bisection and reconstruction; TL: Tree length; UOM: University of Melbourne; WA: Water agar

\section{Acknowledgements}

We wish to thank World Vegetable Center AVDRC, Taiwan; Ratchadawan Cheewangkoon, Faculty of Agriculture, Chiang Mai University, Thailand and Nalika Ranathunge, Faculty of Agriculture, University of Ruhuna, Sri Lanka for their contribution in sample collections. Ulrike Damm is thanked for guidance and helpful suggestions to species identification.We also thank Arien Van Iperen and Mieke Starink-Willemse from the Westerdijk Fungal Biodiversity Institute for technical assistance. DD de Silva gratefully acknowledges the financial

support from the Melbourne International Research Scholarship (MIRS) and Melbourne International Fee Remission Scholarship (MIFRS) awarded by the University of Melbourne.

\section{Adherence to national and international regulations}

The importation and use of isolates adhered to the regulations related to National Plant Health and Quarantine, and the Nagaoya Protocol to the Convention on Biological Diversity.

\section{Funding}

The research was not supported by any external grants, the student and project were supported by the University of Melbourne and the Westerdijk Fungal Biodiversity Institute.

\section{Availability of data and materials}

Alignments and tree files generated during the current study are available in the TreeBASE (accession https://www.treebase.org/treebase-web/home.html; study S23829). All sequence data are available in NCBI Genbank following the accession numbers in the manuscript. 


\section{Authors' contributions}

DD wrote the manuscript, made a substantial contribution to the conception of the study, analysed the isolates, interpreted the sequence data and performed the pathogenicity assays and microscopy. JG assisted in the analyses of the data and advised on the interpretation of the taxonomy. PC contributed to microscopic examination of fungal material, advised on the interpretation of the taxonomy, and was a major contributor in writing the manuscript. PA assisted in the analysing and interpretation of the pathogenicity statistical data, and was a major contributor in writing the manuscript. AN contributed to the collection of isolates. OM contributed to the collection of isolates. PT made a substantial contribution to the conception of the study, and was a major contributor in writing the manuscript and collection of isolates. All the authors read and approved the final manuscript.

\section{Ethics approval and consent to participate}

Not applicable.

\section{Consent for publication}

Not applicable.

\section{Competing interests}

The authors declare that they have no competing interests.

\section{Publisher's Note}

Springer Nature remains neutral with regard to jurisdictional claims in published maps and institutional affiliations.

\section{Author details}

${ }^{1}$ Faculty of Veterinary and Agricultural Sciences, The University of Melbourne, Parkville, VIC 3010, Australia. ${ }^{2}$ Westerdijk Fungal Biodiversity Institute, Uppsalalaan 8, 3584, CT, Utrecht, The Netherlands. ${ }^{3}$ Faculty of Science, The University of Melbourne, Parkville, VIC 3010, Australia. ${ }^{4}$ Department of Plant Pest \& Disease, Universitas Hasanuddin, Makassar, Indonesia. ${ }^{5}$ Department of Horticulture, Faculty of Agriculture at Kamphaeng Saen, Kasetsart University, Kamphaeng Saen Campus, Nakhon Pathom, Thailand.

\section{Received: 18 April 2019 Accepted: 25 April 2019}

\section{Published online: 28 June 2019}

\section{References}

Alahakoon PW, Brown AE, Sreenivasaprasad S (1994) Cross-infection potential of genetic groups of Colletotrichum gloeosporioides on tropical fruits. Physiological and Molecular Plant Pathology 44:93-103

Auyong ASM, Ford R, Taylor PWJ (2015) The role of cutinase and its impact on pathogenicity of Colletotrichum truncatum. Journal of Plant Pathology and Microbiology 6:259-269

Cannon PF, Damm U, Johnston PR, Weir BS (2012) Colletotrichum - current status and future directions. Studies in Mycology 73:181-213

Carbone I, Kohn LM (1999) A method for designing primer sets for speciation studies in filamentous ascomycetes. Mycologia 91:553-556

Choi YW, Hyde KD, Ho WH (1999) Single spore isolation of fungi. Fungal Diversity 3:29-38

Crous PW, Gams W, Stalpers JA, Robert V, Stegehuis G (2004b) MycoBank: an online initiative to launch mycology into the 21 st century. Studies in Mycology 50:19-22

Crous PW, Groenewald JZ, Risède JM, Simoneau P, Hywel-Jones NL (2004a) Calonectria species and their Cylindrocladium anamorphs: species with sphaeropedunculate vesicles. Studies in Mycology 50:415-430

Crous PW, Verkleij GJM, Groenewald JZ, Samson RA (2009) Fungal Biodiversity. In: CBS Laboratory manual series no. 1. Centraalbureau voor Schimmelcultures, Utrecht

Damm U, Cannon PF, Woudenberg JH, Johnston PR, Weir BS et al (2012b) The Colletotrichum boninense species complex. Studies in Mycology 73:1-36

Damm U, Cannon PF, Woudenberg JHC, Crous PW (2012a) The Colletotrichum acutatum species complex. Studies in Mycology 73:37-113

Damm U, Sato T, Alizadeh A, Groenewald JZ, Crous PW (2019) The Colletotrichum dracaenophilum, C. magnum and C. orchidearum species complexes. Studies in Mycology 92:1-46 de Oliveira CVS, Matos KS, de Albuquerque DMC, Hanada RE, da Silva GF (2017) Identification of Colletotrichum isolates from Capsicum chinense in Amazon. Genetics and Molecular Research 16:1-10

De Silva DD, Ades PK, Crous PW, Taylor PWJ (2017a) Colletotrichum species associated with chili anthracnose in Australia. Plant Pathology 66:254-267

De Silva DD, Crous PW, Ades PK, Hyde KD, Taylor PWJ (2017b) Life styles of Colletotrichum species and implications for plant biosecurity. Fungal Biology Reviews 31:155-168

Diao YZ, Zhang C, Liu F, Wang WZ, Liu L et al (2017) Colletotrichum species causing anthracnose disease of chili in China. Persoonia 38:20-37

Guerber JC, Liu B, Correll JC, Johnston PR (2003) Characterization of diversity in Colletotrichum acutatum sensu lato by sequence analysis of two gene introns, mtDNA and intron RFLPs, and mating compatibility. Mycologia 95:872-895

Harp TL, Pernezny K, Ivey MLL, Miller SA, Kuhn PJ, Datnoff L (2008) The etiology of recent pepper anthracnose outbreaks in Florida. Crop Protection 27:1380-1384

James R, Ray J, Tan Y, Shivas R (2014) Colletotrichum siamense, C. theobromicola and C. queenslandicum from several plant species and the identification of $C$. asianum in the Northern Territory, Australia. Australasian Plant Disease Notes 9:138

Johnston PR, Jones D (1997) Relationships among Colletotrichum isolates from fruit-rots assessed using rDNA sequences. Mycologia 89:420-430

Kearse M, Moir R, Wilson A, Stones-Havas S, Cheung M et al (2012) Geneious basic: an integrated and extendable desktop software platform for the organization and analysis of sequence data. Bioinformatics 28:1647-1649

Kim KD, Oh BJ, Yang J (1999) Differential interactions of a Colletotrichum gloeosporioides isolate with green and red pepper fruits. Phytoparasitica 27:97-106

Larkin MA, Blackshields G, Brown NP (2007) CLUSTALW and CLUSTALX version 2.0. Bioinformatics 23:2947-2948

Liu F, Tang G, Zheng X, Li Y, Sun X et al (2016b) Molecular and phenotypic characterization of Colletotrichum species associated with anthracnose disease in peppers from Sichuan Province, China. Scientific Reports 6:1-17

Liu F, Wang M, Damm U, Crous PW, Cai L (2016a) Species boundaries in plant pathogenic fungi: a Colletotrichum case study. BMC Evolutionary Biology $16: 1-14$

Liu F, Weir BS, Damm U, Crous PW, Wang Y, Liu B (2015) Unravelling Colletotrichum species associated with Camellia: employing ApMat and gs loci to resolve species in the C. gloeosporioides complex. Persoonia 35: 63-86

Manamgoda DS, Udayanga D, Cai L, Chukeatirote E, Hyde KD (2013) Endophytic Colletotrichum from tropical grasses with a new species $C$. endophytica. Fungal Diversity 61:107-115

Marin-Felix Y, Groenewald JZ, Cai L, Chen Q, Marincowitz S et al (2017) Genera of phytopathogenic fungi: GOPHY 1. Studies in Mycology 86:99-216

Mongkolporn O, Montri P, Supakaew T, Taylor PWJ (2010) Differential reactions on mature green and ripe chili fruit infected by three Colletotrichum spp. Plant Disease 94:306-310

Mongkolporn O, Taylor PWJ (2018) Chili anthracnose: Colletotrichum taxonomy and pathogenicity. Plant Pathology 67:1255-1263

Nguyen PTH, Vinnere Pettersson O, Olsson P, Liljeroth E (2010) Identification of Colletotrichum species associated with anthracnose disease of coffee in Vietnam. European Journal of Plant Pathology 127:73-87

Nirenberg HI (1976) Untersuchungen über die morphologische und biologischeDifferenzierung in der Fusarium-Sektion Liseola. Mitteilungen aus der Biologischen Bundesanstalt für Land- und Forstwirtschaft Berlin-Dahlem 169:1-117

Noor NM, Zakaria L (2018) Identification and characterization of Colletotrichum spp. associated with chili anthracnose in peninsular Malaysia. European Journal of Plant Pathology 151:961-973

Nylander JAA (2004) MrModeltest v. 2. [Program distributed by the author. Evolutionary Biology Centre, Uppsala University, Uppsala

Page RD (1996) TREEVIEW: an application to display phylogenetic trees on personal computers. Computer Applications in the Biosciences 12:357-358

Prihastuti H, Cai L, Chen H, McKenzie EHC, Hyde KD (2009) Characterization of Colletotrichum species associated with coffee berries in northern Thailand. Fungal Diversity 39:89-109

Ranathunge NP, Hewa Bajjamage PS (2016) Deceptive behaviour of Colletotrichum truncatum: strategic survival as an asymptomatic endophyte on non-host species. Journal of Plant Protection Research 56:157-162 
Ranathunge NP, Mongkolporn O, Ford R, Taylor PWJ (2012) Colletotrichum truncatum pathosystem on Capsicum spp: infection, colonization and defence mechanisms. Australasian Plant Pathology 41:463-73.

Rojas El, Rehner SA, Samuels GJ, Van Bael SA, Herre EA et al (2010) Colletotrichum gloeosporioides s.l. associated with Theobroma cacao and other plants in Panamá: multilocus phylogenies distinguish host-associated pathogens from asymptomatic endophytes. Mycologia 102:1318-1338

Ronquist F, Teslenko M, Mark P, Ayres DL, Darling A, Höhna S (2012) MrBayes 3.2: efficient Bayesian phylogenetic inference and model choice across a large model space. Systematic Biology 61:539-542

Saini TJ, Gupta SG, Char BR, Zehr UB, Anandalakshmi R (2016) First report of chill anthracnose caused by Colletotrichum karstii in India. New Disease Reports 34:6

Sharma G, Kumar N, Weir BS, Hyde KD, Shenoy BD (2013) The ApMat marker can resolve Colletotrichum species: a case study with Mangifera indica. Fungal Diversity 61:117-138

Sharma G, Pinnaka AK, Shenoy BD (2014) Infra-specific diversity of Colletotrichum truncatum associated with chilli anthracnose in India based on microsatellite marker analysis. Archives of Phytopathology and Plant Protection 47:2509-2523

Sharma G, Shenoy BD (2014) Colletotrichum fructicola and C. siamense are involved in chilli anthracnose in India. Archives of Phytopathology and Plant Protection 47:1179-1194

Shivas RG, Tan YP, Edwards J, Dinh Q, Maxwell A et al (2016) Colletotrichum species in Australia. Australasian Plant Pathology 45:447-464

Silva DN, Talhinhas P, Várzea V, Cai L, Paulo OS et al (2012) Application of the Apn2/MAT locus to improve the systematics of the Colletotrichum gloeosporioides complex: an example from coffee (Coffea spp.) hosts. Mycologia 104:396-409

Silva JRA, Chaves TP, da Silva ARG, Barbosa LDF, Costa JFO et al (2017) Molecular and morpho-cultural characterization of Colletotrichum spp. associated with anthracnose on Capsicum spp. in northeastern Brazil. Tropical Plant Pathology 42:315-319

Stephenson SA, Green JR, Manners JM, Maclean DJ (1997) Cloning and characterisation of glutamine synthetase from Colletotrichum gloeosporioides and demonstration of elevated expression during pathogenesis on Stylosanthes quianensis. Current Genetics 31: 447-54

Suwannarat S, Steinkellner S, Songkumarn P, Sangchote S (2017) Diversity of Colletotrichum spp. isolated from chili pepper fruit exhibiting symptoms of anthracnose in Thailand. Mycological Progress 16:677-686

Swofford DL (2003) PAUP*: phylogenetic analysis using parsimony. Version 4.0 beta. Sinauer Associates, Sunderland

Tamura K, Stecher G, Peterson D, Filipski A, Kumar S (2013) MEGA6: molecular evolutionary genetics analysis version 6.0. Molecular Biology and Evolution 30:2725-2729

Than PP, Jeewon R, Hyde KD, Pongsupasamit S, Mongkolporn O, Taylor PWJ (2008) Characterization and pathogenicity of Colletotrichum species associated with anthracnose on chilli (Capsicum spp.) in Thailand. Plant Pathology 57:562-572

Udayanga D, Manamgoda DS, Liu X, Chukeatirote E, Hyde KD (2013) What are the common anthracnose pathogens of tropical fruits? Fungal Diversity 61:165-179

Vieira WAS, Michereff SJ, De Morais MA Jr, Hyde KD, Câmara MPS (2014) Endophytic species of Colletotrichum associated with mango in northeastern Brazil. Fungal Diversity 67:181-202

Voorrips RE, Finkers R, Sanjaya L, Groenwold R (2004) OTL mapping of anthracnose (Colletotrichum spp.) resistance in a cross between Capsicum annuum and C. chinense. Theoretical and Applied Genetics 109:1275-1282

Weir BS, Johnston PR, Damm U (2012) The Colletotrichum gloeosporioides species complex. Studies in Mycology 73:115-180

White TJ, Bruns T, Lee S, Taylor J (1990) Amplification and direct sequencing of fungal ribosomal RNA genes for phylogenetics. In: Innis MA, Gelfand DH, Sninsky JJ, White TJ (eds) PCR Protocols: a guide to methods and applications. Academic Press, San Diego, pp 315-322

Woudenberg JHC, Aveskamp MM, de Gruyter J, Spiers AG, Crous PW (2009) Multiple Didymella teleomorphs are linked to the Phoma clematidina morphotype. Persoonia 22:56-62

Yang YL, Cai L, Yu ZN, Liu ZY, Hyde KD (2011) Colletotrichum species on Orchidaceae in Southwest China. Cryptogamie Mycologie 32:229-253

Yang YL, Liu ZY, Cai L, Hyde KD, Yu ZN, McKenzie EHC (2009) Colletotrichum anthracnose of Amaryllidaceae. Fungal Diversity 39:123-146

Ready to submit your research? Choose BMC and benefit from:

- fast, convenient online submission

- thorough peer review by experienced researchers in your field

- rapid publication on acceptance

- support for research data, including large and complex data types

- gold Open Access which fosters wider collaboration and increased citations

- maximum visibility for your research: over $100 \mathrm{M}$ website views per year

At BMC, research is always in progress.

Learn more biomedcentral.com/submissions 